
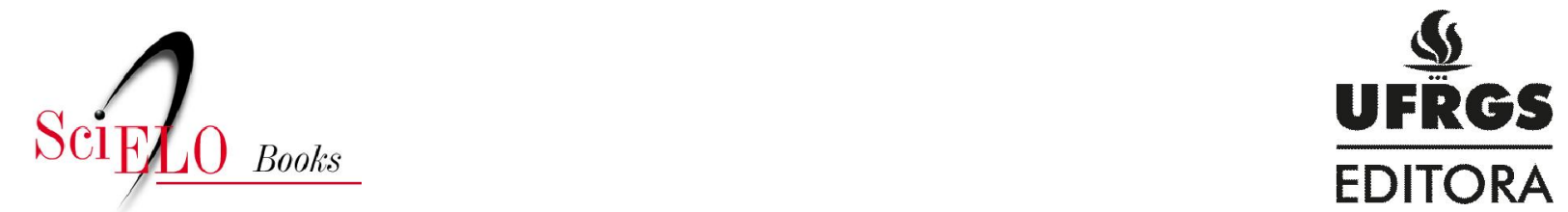

\title{
O paradigma do Estado Desenvolvimentista e o "retorno" da Política Industrial
}

\author{
André Moreira Cunha
}

\section{SciELO Books / SciELO Livros / SciELO Libros}

CUNHA, AM. O paradigma do Estado Desenvolvimentista e o "retorno" da Política Industrial. In: DATHEIN, R., org. Desenvolvimentismo: o conceito, as bases teóricas e as políticas [online]. Porto Alegre: Editora da UFRGS, 2003. Estudos e pesquisas IEPE series, pp. 73-111. ISBN 978-85-3860382-5. Available from doi: 10.7476/9788538603825. Also available in ePUB from: http://books.scielo.org/id/8m95t/epub/dathein-9788538603825.epub.

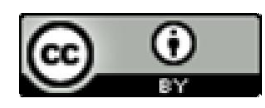

All the contents of this work, except where otherwise noted, is licensed under a Creative Commons Attribution 4.0 International license.

Todo o conteúdo deste trabalho, exceto quando houver ressalva, é publicado sob a licença Creative Commons Atribição 4.0.

Todo el contenido de esta obra, excepto donde se indique lo contrario, está bajo licencia de la licencia $\underline{\text { Creative Commons }}$ $\underline{\text { Reconocimento } 4.0 .}$ 


\section{0 paradigma do Estado Desenvolvimentista e o"retorno" da Política Industrial'}

André Moreira Cunha

\section{Introdução}

O presente capítulo trata do que se tem denominado de um "retorno" de políticas estatais mais ativas. ${ }^{2}$ Argumenta-se que este é o resultado, principalmente, (I) da ascensão dos grandes países emergentes, especialmente a China; (II) da crise financeira global; e (III) da perda de credibilidade do modelo neoliberal. O marco referencial central é o assim-chamado paradigma do "Developmental State" ("Estado desenvolvimentista" ou PED, de agora em diante) associado aos trabalhos seminais de Johnson (1982), Amsden (1989), Wade (1990), Chang (1994), Evans (1995), dentre outros, com seus desdobramentos posteriores (Woo-Cumings, 1999; Chang, 2006; Wang, 2008; Wade, 2010). Em essência, o PED se refere ao conjunto de contribuições para a explicação do desenvolvimento asiático, particularmente do Japão e dos NICs (Newly Industrialized Countries) de primeira geração - Taiwan, Coreia do Sul, Cingapura e Hong Kong - e que analisam o papel das políticas públicas voltadas à construção de novas estruturas produtivas

\footnotetext{
${ }^{1}$ Este trabalho foi realizado com apoio do IPEA no âmbito do projeto "A dimensão produtivo-tecnológica nas teorias do desenvolvimento econômico e suas decorrências normativas: em busca de fundamentos teóricos para as políticas industriais e de CT\&I". Uma versão anterior foi publicada na revista Pesquisa \& Debate, v. 23, p. 291-316, 2012. ${ }^{2}$ Sobre o conceito e escopo das políticas de apoio ao desenvolvimento, especialmente a política industrial, ver Chang (1994), Suzigan e Furtado (2006), Pack e Saggi (2006), Cepal (2007), Cimoli, Dosi e Stiglitz (2009a e 2009b) e Peres e Primi (2009).
} 
e capacidades tecnológicas. As pesquisas associadas ao PED têm enfatizado o estudo das políticas industriais, gerando a conclusão de que o Estado teria sido um ator central na conformação do assim chamado "milagre asiático”. Essa tradição se afasta das explicações convencionais que explicam o sucesso asiático por meio das estratégias de extroversão comercial, com a adoção de políticas comerciais supostamente neutras e manutenção de um ambiente de estabilidade macroeconômica (Balassa, 1970, 1989; Little; Scitovsky; Scott, 1970; Krueger, 1974; World Bank, 1993).

Nossos argumentos estão estruturados da seguinte forma. A seção 2 trata da origem e evolução do PED. A seção 3 trata da importância de se manterem políticas ativas de desenvolvimento nos marcos das transformações estruturais da economia mundial neste início de século XXI. Seguem as considerações finais.

\section{O paradigma do developmental state}

A ideia de que o ativismo estatal está diretamente associado ao progresso econômico das nações remonta, pelo menos, ao período do mercantilismo (Reinert, 2007). O argumento da proteção da indústria infante de Alexander Hamilton e Friedrich List (1841) tornou-se popular em nações emergentes que procuravam reproduzir a trajetória britânica de revolução industrial (Chang, 2002). Da mesma forma, a noção de que o desenvolvimento econômico implica mudança qualitativa das estruturas produtivas, em que as inovações tecnológicas encontram um papel de centralidade, está fortemente assentada na obra de Schumpeter $(1911,1942)$ e encontra ecos na análise de Marx (1867).

Reinert (2007 e 2009) tem argumentado que, em uma perspectiva histórica, é possível constatar que as nações mais bem-sucedidas no processo de acumulação de poder econômico e político e que, adicionalmente, partiram de uma situação de atraso relativo frente aos líderes em cada momento, adotaram, inicialmente, a estratégia da "emulação". Isso implicava necessidade de uma atuação ativa do Estado. Uma vez alcançada a fronteira de eficiência técnica, era possível transitar para uma situação de predomínio das decisões descentralizadas nos termos tradicionais das vantagens comparativas ricardianas. Chang (2002) desenvolve argumento semelhante, ao demonstrar que as economias hoje avançadas lançaram 
mão de políticas que poderiam ser denominadas de desenvolvimentistas, nos termos do PED, nos seus períodos de "arranque".

Entre os anos 1940 e $1950^{3}$, a emergência do desenvolvimento econômico enquanto um campo autônomo de pesquisa introduziu elementos de racionalização da intervenção consciente do Estado na coordenação do processo, até então espontâneo, de industrialização nos países periféricos. Neste sentido, o PED, que nos termos definidos anteriormente ganha corpo intelectual a partir de meados dos anos 1980, não se constitui em experimento intelectual original. Pelo contrário, ele emana, converge e se interliga (Peres; Primi, 2009), com reflexões prévias sobre o desenvolvimento em geral, e sobre a possibilidade de países retardatários em criar condições para a superação do seu atraso relativo. Assim, para os teóricos do imediato pós-guerra era evidente que as falhas de mercado, estruturais nos países periféricos, justificariam a adoção de políticas ativas de apoio à industrialização. Esta, por sua vez, estaria na base da transformação da sociedade, do seu desenvolvimento. ${ }^{4}$

Na década de 1960, iniciou-se uma forte reação neoclássica à teoria do desenvolvimento. ${ }^{5}$ Tendo como norte teórico os modelos de crescimento de Solow (1956) e Swan (1956), bem como a moderna teoria do equilíbrio geral ${ }^{6}$, os economistas convencionais denunciavam que o protecionismo e o dirigismo estatal, nos marcos da industrialização substitutiva de importações, estariam gerando graves distorções de preços e, por decorrência, uma crescente ineficiência alocativa. Esta se manifestaria no viés antiexportação, na transferência de renda do Setor Primário para a indústria, na perda de dinamismo em termos de cresci-

\footnotetext{
${ }^{3}$ Krugman (1993) denominou tal período de high development theory, cujos pioneiros tiveram insights posteriormente incorporados na "nova geografia econômica", nos modelos de crescimento endógeno e na nova teoria do comércio. Autores como Prebisch, Furtado, Nurkse, Rosentein-Rodan, Hirschman, dentre outros, são os destaques do período. ${ }^{4}$ É interessante notar a observação recente de Chang (2009) para quem a noção de que o desenvolvimento está associado a uma mutação radical da base produtiva da sociedade rumo à estruturação de atividades mais complexas teria desaparecido do discurso oficial. Vale dizer, não haveria mais a essência do que os pioneiros do pós-guerra entendiam como sendo desenvolvimento. Observação semelhante pode ser encontrada em Rodrik (2006). ${ }^{5}$ No plano teórico, ver a coletânea organizada por Bhagwati (1969). Para uma survey da literatura teórica e empírica, ver Balassa (1989).

${ }^{6}$ Ver Chang (2006), Peres e Primi (2009).
} 
mento, no baixo desenvolvimento do mercado de capitais, nas recorrentes crises de balanço de pagamentos, na elevada inflação e no predomínio de comportamentos rent-seeking (Krueger, 1974; Noland; PACK, 2003). O esforço de comprovação empírica destes problemas levou à constatação de que países que perseguiam políticas comerciais tidas como neutras, políticas cambiais e monetárias realistas, seriam capazes de reduzir as distorções de preços e acelerar o desenvolvimento. ${ }^{8}$

A partir dos anos 1970, este debate esteve centrado no desempenho das economias asiáticas de industrialização recente. Assim, enquanto parte da periferia, especialmente a América Latina, teria reafirmado sua opção pela estratégia introvertida, os países asiáticos teriam perseguido um conjunto distinto de políticas. Como resultado, houve um descolamento nas trajetórias comparadas das duas regiões. Os asiáticos recobraram-se rapidamente dos choques externos do período - os aumentos no preço do petróleo, o choque de juros e a crise da dívida

\footnotetext{
${ }^{7} \mathrm{Na}$ perspectiva estruturalista, tanto os problemas de inflação quanto de balanço de pagamentos seriam uma decorrência dos desequilíbrios estruturais das economias periféricas, agravados pelo crescimento acelerado: o menor dinamismo do setor agrícola em um contexto de forte urbanização, a escassez de dólares - agravada pela reação do Banco Mundial e FMI, contrários ao intervencionismo "inflacionário" que, na sua opinião, geraria os desequilíbrios interno e externo - as descontinuidades setoriais decorrentes dos big pushes etc. Por outro lado, como argumentado anteriormente, o pessimismo exportador não era gratuito; bem como o otimismo intervencionista. Ainda assim, é importante lembrar que os economistas neoclássicos não detêm o monopólio da crítica às ineficiências geradas pelo processo de substituição de importações. Já nos anos 1960 os relatórios anuais da CEPAL apontavam para a necessidade de reverter o viés antiexportação.

${ }^{8}$ Balassa (1970) compara o desempenho de um conjunto de economias "semi-industrializadas", encontrando um desempenho superior nas que seguiam uma estratégia de extroversão (Dinamarca e Noruega), em relação às de estratégia introvertida (Argentina e Chile) e às economias socialistas (Hungria e Checoslováquia). Desempenho manifesto em termos de crescimento do produto, eficiência dos investimentos e acesso à poupança externa, devido a um maior dinamismo exportador. Dinamarca e Noruega teriam eliminado as restrições quantitativas às importações, reduzido suas tarifas alfandegárias a níveis inferiores à média dos países desenvolvidos, bem como adotado políticas cambiais realistas e de juros reais positivos. No trabalho clássico de Little et al (1970) estuda-se o desempenho comparativo de Argentina, Brasil, México, Índia, Paquistão, Filipinas e Taiwan. Da mesma forma que Balassa (1970), faz-se a crítica às distorções geradas pela industrialização substitutiva de importações. Além disso, procura-se associar as reformas realizadas nos anos $1960 \mathrm{em}$ alguns dos países, no sentido de reduzir o viés antiexportação, aos níveis mais elevados de crescimento e bem estar (melhor distribuição de renda).
} 
do início dos anos 1980 - e consolidaram um processo sustentado de crescimento com estabilidade. Alguns países latinos mantiveram certo fôlego na década de 1970, mas adentraram os anos 1980 com reduzido crescimento e forte instabilidade.

Tomando por referência o debate em torno do "milagre asiático", é possível identificar ondas de interpretações entre os economistas de formação neoclássica, muitos deles vinculados a instituições multilaterais como o Banco Mundial e o FMI. Nesta perspectiva, o desempenho superior das economias asiáticas passou a servir de base para a afirmação de que um conjunto de políticas específicas seria mais adequado para garantir crescimento com estabilidade para aqueles países em desenvolvimento desejosos de replicar o sucesso asiático. Em essência, tratava-se de delimitar a ação estatal, combinada a certo regime ou estratégia comercial, em que caberia ao Estado (I) definir o arcabouço institucional de referência para as decisões privadas, ou seja, garantir o direito de propriedade e, assim, de transferência dos ativos (físicos, financeiros e intelectuais); (II) estabelecer informações e regulação dos padrões de ampla utilização (pesos, medidas, normas de segurança no trabalho, etc.); (III) através da política fiscal e monetária, garantir a estabilidade macroeconômica; e (IV) através do regime comercial aproximar os preços internos dos externos, estabelecendo critérios mais rígidos de eficiência para as decisões de alocação. Em alguns casos, ao se assumir a existência de falhas de mercado, admitia-se a provisão de bens, serviços e infraestrutura (Little et al, 1970; World Bank, 1987, 1993; Balassa, 1989; Pack, 1988).

As tabelas e gráficos em Anexo permitem delinear o contexto e a evolução desse debate. Os países asiáticos ${ }^{9}$ passaram a descolar das demais regiões periféricas em termos de crescimento, participação na

\footnotetext{
${ }^{9}$ Não é trivial delimitar este grupo de países, normalmente agrupados em um conjunto denominado de "Leste Asiático" (Wang, 2008). A primeira geração de debates se centrou na análise do Japão, Coreia do Sul, Taiwan, Cingapura e Hong Kong, localizados geograficamente no nordeste da Ásia. Os quatro últimos passaram a ser denominados de "Tigres Asiáticos" ou NICs Asiáticos (Newly Industrialized Countries). A partir de meados dos anos 1980, o "Leste" foi ampliado, incorporando países do sudeste daquela região, tais como Malásia, Tailândia, Indonésia e Filipinas, também chamados de "Tigrinhos" ou NICs Asiáticos de segunda geração. Eventualmente, a China passou a configurar neste universo. Há amplas diferenças culturais, de regimes políticos, de etnias e ocupação de espaços geográficos ao longo da história por parte destas nações, de modo que os
} 
renda e nas exportações mundiais, bem como de estruturação de bases produtivas mais diversificadas e complexas do que as verificadas em outras regiões. E esse processo se deu com aqueles países partindo de uma base de desenvolvimento econômico e social inferior à verificada na América Latina em geral e, mesmo, àquela encontrada em muitos países africanos (Chang, 2006).

A Tabela 1 mostra que, em 2009, os países em desenvolvimento da Ásia e os assim chamados NICs (Coreia do Sul, Taiwan, Cingapura e Honk Kong) representavam 54\% da população mundial, $26 \%$ da renda e $24 \%$ das exportações. Ao se incluir o Japão, o peso econômico regional chegaria a cerca de $1 / 3$ dos totais mundiais. $O$ dinamismo asiático no período da globalização inaugurada no último quartel do século XX pode se expressar da seguinte forma: se, em 1980, a América Latina representava $10 \%$ do PIB mundial medido em paridade, poder de compra, a Ásia em desenvolvimento acrescida de seus NICs atingia 9\%. Três décadas depois, a América Latina detinha 8,5\% do PIB global, ao passo que a Ásia chegava a deter 26\%. Enquanto os países asiáticos cresciam a taxas médias de $7 \%$ ao ano, os países latino-americanos e africanos experimentavam ritmos bastante inferiores, entre $2 \%$ e $3 \%$.

Os Gráficos 1 e 2 contam a mesma história, com as principais economias latino-americanas estagnadas com uma participação na renda mundial oscilando em torno de 5,5\% no período $1960-2008$, ao passo que as economias asiáticas partem de um nível de participação equivalente para algo duas vezes superior, dependendo da inclusão ou não do Japão. A Tabela 2 mostra que, enquanto o conjunto dos países em desenvolvimento passa a ter uma menor participação nos estoques mundiais de investimento direto estrangeiro, os asiáticos mais do que dobram seu espaço entre os anos de 1980 e 2009. O Gráfico 3 sugere que, até meados dos anos 1970, as principais economias em desenvolvimento da Ásia e da América Latina detinham participações semelhan-

estudos sobre o desenvolvimento da Ásia sempre iniciam delimitando o subconjunto de países que serão tratados. Aqui, a ênfase também recairá sobre Japão e os NICs de primeira e segunda gerações, aí incluindo a China. Todavia, as bases estatísticas do Banco Mundial, FMI, Unctad, etc. fazem agregações mais amplas ou mesmo mais restritas, de modo que cada gráfico ou tabela do Anexo estará referido a uma daquelas fontes e, portanto, o leitor deverá, eventualmente, consultar aquelas bases para ter uma noção mais precisa dos países envolvidos. 
tes nas exportações mundiais. Todavia, enquanto as economias asiáticas quadruplicaram seu market-share, as economias latino-americanas permaneceram praticamente na mesma situação.

Cabe ressaltar que este crescimento veio acompanhado de profundas mudanças estruturais (Tabelas 3 e 4). Verificaram-se intensa urbanização, perda relativa de importância da agricultura na geração da renda e forte elevação da participação do comércio exterior no PIB. Em nenhuma outra região do mundo, as exportações de bens e serviços ampliaram-se de um modo tão veloz. Ademais, a estrutura das exportações, refletindo a profunda transformação na base produtivas daquelas economias, passou a se caracterizar pelo predomínio de manufaturas de maior conteúdo tecnológico (Gráficos 4 e 7). A comparação entre Ásia e América Latina evidencia as dificuldades das economias dos países latino-americanos em manter estruturas produtivas e de comércio exterior mais densas e sofisticadas. A partir dos anos 1980, os países asiáticos ampliam sua internacionalização, mantendo níveis elevados de participação da indústria no PIB, ao passo que os latino-americanos assistem a uma queda importante na participação da indústria na renda. Isto se dá em um contexto de redução dos níveis de formação bruta de capital na América Latina, para valores médios abaixo de $20 \%$ do PIB, enquanto na Ásia as economias mais dinâmicas mantiveram investimentos próximos a $30 \%$ do PIB ${ }^{10}$ pode ser visto na Tabela 3 (Palma, 2004; Cepal, 2007; Carneiro, 2007). Não à toa, a perda de dinamismo da indústria está associada a um período de retração no crescimento da renda.

O Gráfico 5 ilustra os efeitos do padrão diferenciado de crescimento sobre a renda por habitante das principais economias das duas regiões. Percebe-se que, até a crise da dívida externa, no começo dos anos 1980, as principais economias latino-americanas vinham em um processo de redução do gap de renda per capita frente aos EUA, em um ritmo tão intenso quanto o verificado na Ásia. A partir de então, há uma nítida divergência de desempenhos, com as principais nações asiáticas mantendo sua tendência de convergência e com os países latino-americanos estagnados ou retrocedendo, à exceção do Chile. Esse fato vai ao encontro das considerações de Rodrik (2006), à medida

${ }^{10}$ Depois da crise financeira de 1997 e 1998, houve um declínio nos investimentos, especialmente nos países da ASEAN. 
que, para este autor, há evidências empíricas robustas que sugerem a existência de uma correlação forte entre a aceleração do crescimento e a existência de estruturas produtivas diversificadas e com elevada participação da indústria de transformação. Aparentemente, as economias asiáticas lograram manter uma base produtiva industrial densa e diversificada, com impactos diretos sobre as respectivas pautas de exportações, com a presença crescente das manufaturas intensivas em tecnologia.

Os países asiáticos mais dinâmicos também se destacam na tentativa de manter um padrão de desenvolvimento cada vez mais alicerçado em setores portadores das inovações tecnológicas e que têm transformando a base produtiva e os padrões de consumo nas últimas três décadas. $\mathrm{O}$ Gráfico 6 mostra que países como Coreia do Sul, Cingapura e Japão estão entre os que mais investem em pesquisa e desenvolvimento (P\&D). A Coreia do Sul merece uma menção especial, à medida que seu esforço para alcançar as nações que determinam as fronteiras tecnoprodutivas se traduz em um gasto em P\&D que, na média do período 2001-2007, ficou abaixo apenas da Suécia, Finlândia, Japão e Suíça. E isso se deu a despeito de sua renda per capita equivaler a algo entre 50\% e $60 \%$ da renda per capita das nações mais ricas. A China também vem realizando um avanço nesta área. Entre 1996 e 2000, seus gastos em P\&D foram, em média, de 0,7\% do PIB. Entre 2001 e 2007, tais investimentos alcançaram 1,3\% do PIB. Para se colocar em perspectiva, os gastos do Brasil foram, nestes dois momentos, de $0,8 \%$ e $0,9 \%$ do PIB. A despeito de despontar como um líder regional em investimentos em $\mathrm{P} \& \mathrm{D}, \mathrm{o}$ Brasil segue muito atrás das economias asiáticas mais dinâmicas.

Os asiáticos lideram os investimentos em tecnologias de informação, equipamentos e softwares (Gráfico 8), em infraestrutura para dar sustentação a esses setores (Gráfico 9) e em termos de manutenção de um ambiente de negócios favorável às empresas. Tais aspectos merecem ser explorados mais adiante, à medida que políticas industriais voltadas para o fortalecimento e diversificação produtiva no século XXI devem estar sintonizadas com a necessidade de ampliar a capacidade dos empreendedores locais em avançar nas fronteiras tecnológicas abertas nos mais diversos setores, do agronegócio às tecnologias de informação. Esse é um ponto de convergência entre visões distintas, como as de Jomo (2005), Unctad (2006), Chang (2009, 2010), Peres e Primi (2009), Rodrik (2004, 2006, 2009), Cimoli, Dosi e Stiglitz 
(2009a, 2009b), dentre outros, mais próximas à tradição do PED, e as de Canuto, Dutz e Reis (2010), Lin (2010) e Lin e Monga (2010) que refletem a perspectiva do Banco Mundial e do mainstream da Economia, geralmente avesso às políticas mais ativas.

Também é importante lembrar que, no caso asiático, o crescimento esteve associado a uma sensível ampliação na qualidade de vida da população em geral, expressa em indicadores como o aumento do consumo per capita, do acesso à água tratada, da escolaridade, a redução da mortalidade infantil etc. ${ }^{11}$ Variável síntese deste processo é o indicador de desenvolvimento produzido pelo Programa das Nações Unidas para o Desenvolvimento Humano, reportado na Tabela 5, em Anexo. Por fim, cabe salientar que, em comparação com outros países de desenvolvimento tardio, é possível verificar que, na Ásia, os níveis de inflação e os resultados fiscais foram relativamente mais favoráveis. Todavia, esses países não ficaram imunes às crises internacionais dos anos 1970, 1980 e 1990, e alguns conviveram com elevados déficits externos e eventuais surtos inflacionários. Em geral, os principais indicadores macroeconômicos sinalizam o fato de que as economias mais avançadas da região, como Japão, Coreia do Sul, Taiwan, Hong Kong e Cingapura, tenderam a ter um desempenho mais favorável do que os países relativamente menos desenvolvidos, tais como aqueles que compõem a ASEAN. ${ }^{12}$ Estes, por sua vez, mantiveram um comportamento mais próximo ao dos países latino-americanos (World Bank, 1993, 2005; Birsdall; Jaspersen, 1997; Jomo, 2005; Singh, 2009).

Assim, a reafirmação do sucesso asiático tem estado no centro dos debates em torno das estratégias de desenvolvimento, com o paradigma do Estado Desenvolvimentista emergindo, originalmente, como uma tentativa de explicar a singularidade japonesa (Johnson, 1982) sendo, posteriormente, estendido para outros casos de sucesso, como Coreia

\footnotetext{
${ }^{11}$ Optou-se por evitar aqui uma exposição exaustiva dos dados. Os Relatórios Anuais do Banco Mundial (World Development Indicators, World Development Reports) e da ONU (UNDP Human Development Reports) mostram que os países asiáticos vêm apresentando, ao longo das últimas décadas, melhorias significativas em virtualmente todos os indicadores de desenvolvimento humano, em um ritmo superior ao conjunto dos países em desenvolvimento. Detalhes em World Bank (1993, 2008) e Chang (2006).

${ }^{12}$ Association of South-East Asian Nations (Associação das Nações do Sudeste Asiático): Indonésia, Malásia, Tailândia, Filipinas, Cingapura, Laos, Brunei, Camboja, Vietnã e Miamar.
} 
do Sul, Taiwan e Cingapura (Amsden, 1989; Wade, 1990; Chang, 1993, 2006). Para Johnson $(1982,1987,1999)$ é importante identificar o "Estado desenvolvimentista" como aquele que, por meio de um processo sistemático de intervenções no sistema econômico, coloca o desenvolvimento econômico como prioridade. Tal Estado seria uma terceira via entre o planejamento central no estilo soviético e o menor nível de ativismo estatal do modelo anglo-saxônico, centrado nas decisões privadas. A racionalidade do planejamento indicativo do Estado associados a um setor privado forte teria garantido as condições para que o Japão recuperasse seu poder relativo frente ao mundo ocidental. Determinantes dessa natureza, como "segurança nacional", "construção da nação", busca de "autonomia" e "independência" aparecem nos estudos específicos dos outros países asiáticos (Woo-Cumings, 1999; Chang, 2006; Wang, 2008).

\section{O paradigma do developmental state no século XXI}

A avaliação da experiência asiática à luz do PED nos conduz à percepção de que não existe um único modelo de industrialização bem-sucedida. Se a orientação exportadora, os investimentos em qualificação do capital humano e a intervenção do Estado são pontos em comum, o contexto histórico e os objetivos industriais - e, com isso, os instrumentos utilizados - foram distintos. Os diferentes objetivos de cada país, especialmente no que se refere ao aprofundamento da industrialização, teriam implicado posições distintas frente ao investimento direto externo (IDE). Cingapura, por exemplo, seria mais liberal neste aspecto, tendo montado seu drive exportador com base nas empresas transnacionais. Isso teria implicado um menor esforço tecnológico local. Já Coreia e Taiwan teriam tido o comportamento inverso. Incentivaram o desenvolvimento tecnológico local, a cargo de empresas nacionais - grandes conglomerados na Coreia, pequenas e médias empresas e estatais em Taiwan. Isto restringiu a participação das empresas transnacionais. A experiência de Hong Kong seria mais próxima ao comportamento imaginado pelo paradigma neoclássico, com uma menor seletividade nas políticas, posto que o aprofundamento na industrialização não se mostrou fundamental em sua dinâmica de modernização. Já países como Malásia e Tailândia, com maior ênfase, e Filipinas e Indonésia (Jomo, 2001, 2005) se utilizaram de estratégias 
mais próximas às verificadas em outras economias retardatárias, particularmente na América Latina e Leste Europeu, estruturando sua base produtiva industrial com forte presença de IDE (Tabela 2, em anexo).

Como síntese do debate que antecedeu a crise financeira de 19971998, é importante enfatizar que o estudo clássico do Banco Mundial sobre o "milagre asiático" (World Bank, 1993) não deixou de ser um avanço. O Banco Mundial não negaria mais as evidências de que as políticas intervencionistas tiveram uma presença marcante na trajetória de crescimento das principais economias asiáticas. O debate deslocou-se nitidamente para a questão de quais políticas são mais eficientes, ao espírito recentemente proposto por Rodrik (2009). Verificou-se alguma convergência no que se refere às preocupações quanto aos efeitos adversos de políticas de estímulo a setores específicos sem a exigência de contrapartidas em termos de desempenho exportador e/ou tecnológico. Isso implicaria necessidade de que as políticas seletivas devem ser articuladas, de modo a não só coordenar os investimentos, mas, também, garantir sua eficiência. ${ }^{13}$ Para os adeptos do PED, a proteção seletiva se justifica e é necessária em certos casos. Ela deve ser (I) limitada no tempo, associada a um monitoramento efetivo e eficaz com a imposição de requerimentos de desempenho; (II) acompanhada do incentivo à concorrência, especialmente nos mercados externos - o mercado interno protegido pode, em um dado momento, ser uma forma de garantir escalas de produção; e (III) atenta ao desenvolvimento da capacitação tecnológica e organizacional endógena, lembrando-se que o ambiente em que a firma interage apresenta múltiplas dimensões e que, assim, não bastaria a proteção dos mercados de bens finais para garantir sua capacitação - ter-se-ia de considerar os mercados de fatores, os mercados financeiros, tecnológicos, a infraestrutura etc.

A literatura do PED tem enfatizado o estudo detalhado das experiências nacionais de desenvolvimento. ${ }^{14}$ Comparações entre países e regiões

\footnotetext{
${ }^{13}$ Essa ressalva do autor também está presente no estudo do Banco Mundial (World Bank, 1993) e na maioria dos intérpretes heterodoxos da experiência asiática.

${ }^{14}$ É importante registrar que a literatura crítica, particularmente nas vertentes da teoria da dependência, já havia alertado para as dificuldades (senão da impossibilidade) dos Estados Nacionais da América Latina liderarem projetos desenvolvimentistas com maiores graus de autonomia frente aos interesses das elites tradicionais e dos poderes forâneos. Santos (2000) resgata as origens e desdobramentos da teoria da dependência. Tavares (1986) analisa o caso brasileiro.
} 
que apresentaram, ao longo do tempo, desempenhos cada vez mais divergentes, como no caso de Ásia e da América Latina, conduzem ao questionamento sobre as razões que levaram a resultados tão distintos diante da utilização de incentivos semelhantes. Vale dizer, nas principais economias destas duas regiões, as políticas desenvolvimentistas envolveram a criação de quase-rendas que foram apropriadas por empresas privadas e/ou estatais com o intuito de promover novos setores produtivos ou modernizar a estrutura produtiva preexistente. Tais quase-rendas nasceram da proteção ao mercado interno, de incentivos fiscais, creditícios, cambiais etc. Enquanto nas economias mais bem-sucedidas da Ásia os incentivos vieram acompanhados de mecanismos que impunham o disciplinamento no uso das quase-rendas, de modo a garantir o aprimoramento das capacidades produtivas em nível microeconômico, na América Latina "as empresas receberam incentivos consideráveis, mas se defrontaram com pouca disciplina." (Di Maio, 2009 p. 21, tradução do autor). ${ }^{15}$

O período de ampliação na divergência de desempenho entre as economias periféricas coincidiu com mudanças estruturais profundas na economia e na política. Houve, por um lado, aprofundamento da interpenetração dos mercados nacionais no âmbito da globalização nos marcos da introdução de novas tecnologias que revolucionaram os padrões de produção e consumo. Por outro, o retorno do liberalismo, a crise do Estado de Bem-Estar e dos regimes de planejamento central e a disseminação de acordos de comércio e investimento de caráter multilateral, no âmbito do GATT-OMC, regional e bilateral implicaram redução no escopo da capacidade dos Estados nacionais adotarem políticas desen-

\footnotetext{
15 "But still, why (apparently) similar industrial policies produced so different results in the East Asian Tigers and Latin America? It is by now a shared view that the recipe of the success of the East Asian Tigers has been the effective combination of incentives with discipline ... The former were provided through subsides and protection, while the latter was obtained through direct government control and the use of export performance as a selection and monitoring device for both the entrepreneurs and the bureaucrats. The failure of the Latin American experience lies precisely in the lack of the joint presence of these two elements. Indeed, during the ISI period Latin American firms received considerable incentives, but faced very little discipline. The mistake has been to ignore efficiency considerations and to assume away capability problems. The idea was actually that the necessary capabilities were already available within the country, or, in case of necessity, they would be created automatically and without extra cost ..." (Di Maio, 2009 p. 21)
} 
volvimentistas nos moldes previamente mencionados (Rodrik, 2004; UNCTAD, 2006; Cepal, 2007; Di Maio, 2009; Peres e Primi, 2009).

Assim, por exemplo, mecanismos de estímulo à produção doméstica, mesmo que voltada para a exportação, foram banidos ou têm o uso muito restrito pelas regras da OMC. Com exceção de países de baixa renda, os subsídios à exportação foram proibidos, bem como as exigências de conteúdo local ou restrições quantitativas às importações. No passado, tais medidas eram utilizadas para atrair empresas transnacionais e/ou criar espaços para a proteção da indústria infante. A possibilidade de fazer engenharia reversa foi severamente limitada por efeito Acordo TRIPS. ${ }^{16}$ Todavia, há espaço para incentivos nos casos de políticas voltadas para o desenvolvimento de novas tecnologias ( $\mathrm{P} \& \mathrm{D}$, incentivos para empresas se instalarem em parques tecnológicos etc.), para o desenvolvimento regional e para atividades que promovam sustentabilidade ambiental. A segurança nacional também pode ser invocada para a criação de excepcionalidades que legitimem políticas seletivas. Medidas de salvaguarda podem ser utilizadas em casos especiais, nos quais a elevação das importações implique desestabilização do balanço de pagamento ${ }^{17}$ ou possibilidade de desestruturação grave de um setor produtivo. ${ }^{18}$

O neoliberalismo e a globalização conformaram um ambiente internacional em que caíram barreiras comerciais tarifárias e custos de transação associados ao transporte e às comunicações. Todavia, isso não se traduziu em um quadro de livre comércio aos moldes de um livro-texto. Não são os mercados atomizados que comandam os fluxos de comércio e de investimentos, mas sim as empresas multinacionais, com suas cadeias hierarquizadas de valor (Jomo, 2005; Haque, 2006; Chang, 2006). ${ }^{19}$ Estas se localizam, predominantemente, nas economias industrializadas e dominam os processos de conformação e disse-

${ }^{16} \mathrm{O}$ Trade-Related Aspects of Intellectual Property Rights (Acordo Relativo aos Aspectos do Direito da Propriedade Intelectual Relacionados com o Comércio). Disponível em: <http:// www.wto.org/english/docs_e/legal_e/ursum_e.htm\#nAgreement >. Acesso em: set. 2010. ${ }^{17}$ Conforme os artigos XII e XVIII do Acordo GATT-OMC Disponível em: <http://www. wto.org/english/docs_e/legal_e/09-bops_e.htm\#fntext3>. Acesso em: set. 2010.

${ }^{18}$ Conforme o artigo XIX do Acordo Geral GATT-OMC Disponível em: <http://www. wto.org/english/docs_e/legal_e/ursum_e.htm\#lAgreement $>$. Acesso em: set. 2010.

${ }^{19}$ Estes autores citam estimativas que tais empresas controlam cerca de $2 / 3$ das exportações mundiais. 
minação das novas tecnologias, incorporadas em produtos, processos de produção e comercialização e ativos intangíveis, como as marcas e patentes. Os governos nacionais das economias industrializadas não se furtam a apoiar os interesses globais de suas empresas, ao passo que os países periféricos buscam capturar parcelas dessas cadeias de produção. Isto implica que é a "estratégia" (de grandes empresas e governos), e não os mercados concorrenciais, que molda as forças econômicas internacionais (Reinert, 2007, 2009). Os governos não abrem mão de suas estratégias desenvolvimentistas, que devem ser adaptadas com o passar do tempo (UNCTAD, 2006; Peres; Primi, 2009).

Esta constatação é corrente entre os autores alinhados à tradição do PED e ganha reforço quando admitida por analistas e instituições multilaterais usualmente mais avessas ao ativismo estatal (Canuto; Giugale, 2010; Lin, 2010; Lin; Monga, 2010; World Bank, 2010). Canuto, Dutz e Reis (2010) e World Bank (2010) sugerem que as políticas de inovação tecnológica devem estar no centro das estratégias de desenvolvimento das economias periféricas. Eles partem da constatação de que há tendências recentes de transformação da economia mundial que estão criando espaços para que os países em desenvolvimento possam reduzir sua defasagem relativa em termos de inovação e de produtividade. Assim, a decomposição da produção nas cadeias hierarquizadas de valor e a disseminação das tecnologias de informação, aliadas ao dinamismo de crescimento dos países emergentes e maior comércio Sul-Sul ${ }^{20}$ criam mais oportunidades para que as empresas localizadas no mundo em desenvolvimento possam inovar, adaptando e criando novas tecnologias a partir de suas especificidades ${ }^{21}$ e, com isso, ampliando suas

\footnotetext{
${ }^{20}$ Canuto, Dutz e Reis (2010) informam que 39\% do total comercializado por países de renda baixa e média se direcionam para seus pares.

${ }_{21}$ "The recent growth of developing economies is associated with a long-term trend rather than with cyclical fluctuations, suggesting a sustainable process... An implication of this trend is that selected enterprises have started new and disruptive forms of innovation in low-income economies... This new approach to innovation, also called "frugal," "constraintbased," or "reverse" innovation (The Economist 2010), is premised on the reality of growing technological capabilities in a number of developing economies, in the significant incentives provided by large and rapidly growing (albeit low-income) local consumer markets, and in low labor costs. The continued growth in emerging economies has opened the opportunity for developing countries to "piggyfrog", a combination of piggybacking on foreign technolo-
} 
possibilidades de inserção em mercados cada vez mais competitivos e globalizados. Para além do esforço de "estar na fronteira", os países periféricos devem apostar na redução das diferenças e, portanto, na exploração dos ganhos potenciais de produtividade. ${ }^{22}$

A agenda de políticas que emerge desta perspectiva é, em linhas gerais, um desdobramento das abordagens anteriores do Banco Mundial. As intervenções são do tipo horizontal, envolvendo (I) a criação de incentivos para um "empreendedorismo produtivo", vale dizer proteção às rendas geradas pela iniciativa inovadora e à propriedade, associadas às pressões competitivas que minimizem "desvio das ações inovadoras"; (II) o desenvolvimento de novas habilidades por meio da formação de recursos humanos, apoio ao P\&D, estreitamento das relações entre empresas e universidades, programas de bolsas de estudos no exterior etc.; (III) a manutenção de um fluxo aberto de informações, enfatizando a abertura comercial, a atração de investimento direto estrangeiro, estímulos para que as empresas multinacionais gerem efeitos de transbordamento pelo treinamento de trabalhadores e gestores locais, ampliação do acesso às novas tecnologias de informação, particularmente a internet etc.; e (IV) o provimento de financiamento por meio de instituições privadas e públicas (Canuto; Dutz; Reis, 2010). O Banco Mundial tem defendido a importância das economias em desenvolvimento se apropriarem de inovações criadas nas economias centrais, garantindo sua adaptação e difusão por meio de um amplo leque de intervenções do tipo horizontal (World Bank, 2010).

Cabe observar que o foco na inovação tecnológica tem sido defendido por autores mais próximos à tradição do $\mathrm{PED}$, tais como Chang

gies by imitating them combined with leapfrogging by adapting these technologies through lower-cost solutions. Examples include Tata Motors' US\$2,200 Nano car aimed at India's lower-middle class, with low-cost engineering adaptations such as one windshield wiper, tubeless tires, and a two-cyliner engine with top speed of 65 miles per hour (105 kilometers per hour), and Tata Consulting Services' US\$24 Swach (Hindi for “clean") water filter targeted at rural households with no electricity or running water, with adaptations such as use of one of the country's most common waste products, ash from rice milling, to filter out bacteria". (Canuto; Dutz; Reis 2010 p.57).

22 "The main message is that developing countries should prioritize diffusion, technological learning, and the adaptation of more efficient existing technologies for productivity upgrading and for the sustainable generation of more and better jobs." (Canuto; Dutz; Reis 2010 p. 53). 
(1994, 2006), Suzigan e Furtado (2006), Cepal (2007), Unctad (2006), Cimoli, Dosi e Stiglitz (2009a, 2009b), Peres e Primi (2009), dentre outros. Com isso as sugestões de Canuto, Dutz e Reis (2010), consubstanciadas nas análises de Noland e Pack (2003), Pack e Saggi (2006), Canuto e Giugale (2010), Lin (2010), Lin e Monga (2010) e World Bank (2010), poderiam muito bem compor um cardápio de intervenções políticas ao espírito do PED. Ainda assim, conforme Chang (1994, 2006, 2009) tem destacado, a existência de seletividade (escolha de setores e/ ou empresas) está na essência das políticas industriais e de inovação, o que conduz a níveis mais elevados de ativismo estatal do que os supostos pelas visões convencionais. Se a visão convencional atual admite a importância das inovações tecnológicas ${ }^{23}$ e das políticas públicas ${ }^{24}$, ela segue rejeitando a seletividade. ${ }^{25}$

A importância da política industrial se reafirma a partir das evidências apontadas por Rodrik (2006). Seus fatos estilizados, baseados em evidências produzidas pela recente literatura empírica sobre os determinantes do crescimento, sugerem que: 1) o crescimento econômico está fortemente correlacionado com a diversificação das atividades produtivas e não com a especialização, conforme sugerido pelos modelos clássico e neoclássico de comércio internacional; 2) países que crescem mais rápido possuem setores industriais maiores como proporção da renda; 3) a aceleração no ritmo de crescimento se dá, com maior intensidade, em países que estão mudando suas estruturas produtivas em direção a setores mais complexos, particularmente a indústria de transformação e, também, ampliando o grau de sofisticação de suas exportações. Portanto, políticas desenvolvimentistas focadas na modernização e na diversificação do Setor Produtivo Industrial ganham maior relevância, o que garante a contemporaneidade das reflexões tributárias do PED.

\footnotetext{
${ }_{23}$ "The rationale for innovation policies is that they aim to boost technological change, which is considered the basic factor of economic growth, social development and environmental adaptation." (World Bank, 2010 p.18)

24 "Governments have traditionally played an important role promoting technology, sometimes by directly supporting the development of technologies (in space, defense, and the like) or more indirectly by creating a climate favorable to innovation through various incentives or laws." (World Bank, 2010 p. 7)

25 "The goal is not pick winners but to create a dynamic and receptive climate in which innovative initiatives in specific industries can be articulated and implemented." (World Bank, 2010 p. 18)
} 
A relevância da criação de novas tecnologias e sua difusão como forma de gerar ganhos de produtividade e, com isso, crescimento da renda, se soma aos desafios das transformações do meio ambiente e da ascensão das economias emergentes. A crise financeira global tem recolocado no centro do debate e das ações de política econômica o papel do Estado na promoção do desenvolvimento. Já é possível identificar o que pode ser a emergência de uma nova rodada de disputas entre as interpretações convencionais e heterodoxas. Os recentes trabalhos do Banco Mundial, mencionados anteriormente, representam um avanço sobre a agenda do Consenso de Washington, ainda que se limitem à defesa de políticas com recortes horizontais e de adaptação e disseminação entre os países em desenvolvimento das inovações tecnológicas geradas no centro capitalista. Mesmo reconhecendo que as regras da OMC são um empecilho para a "ascensão do resto", algo que vem sendo observado há muito tempo pelos autores do PED (Amsden, 2001, 2007; Reinert, 2007; Chang, 2002, 2007), o Banco Mundial reitera que os países devem evitar políticas de "escolha de vencedores", quer sejam setores ou empresas específicas (World Bank, 2010). Com este mesmo espírito, a Revista The Economist (2010) percebe que as pressões depressivas sobre a economia real do período pós-crise têm levado ao que considera um retorno da política industrial. Esta é resumida como sendo fruto de lobbies protecionistas setoriais que, inevitavelmente, conduzirão ao desperdício de recursos públicos.

Rodrik (2010) e Wade (2010) vislumbram neste cenário a possibilidade de se recolocar a discussão sobre a política industrial em torno da sua qualidade e efetividade. Desde logo, este e outros autores mais próximos à tradição do $\mathrm{PED}$ vêm argumentando que, a despeito do Consenso de Washington e, com isso, da retórica contrária às políticas de desenvolvimento mais pró-ativas, vários governos de países desenvolvidos e em desenvolvimento não abriram mão de suas estratégias nacionais. Se tomarmos o exemplo das economias asiáticas, a busca de projetar novos setores e modernizar os já existentes jamais saiu da agenda. A Coreia do Sul, com seu "Ministério da Economia do Conhecimento" aposta em novas tecnologias em setores estratégicos ${ }^{26}$ - energias limpas, tecnologias

\footnotetext{
26 "A knowledge economy embeds traditional goods and services with a premium derived from greater levels of research and innovation intelligence. Korea is turning its focus to accentuate the production of these globally-competitive, value-added goods and services. Dif-
} 
de informação, robótica, nanotecnologia etc. - capazes de garantir a competitividade de seus produtos e serviços. As políticas comercial, industrial e energética envolvem ações tanto horizontais, quanto verticais e de "fronteira". De forma semelhante, os governos de Cingapura ${ }^{27}$, Taiwan $^{28}$, Japão ${ }^{29}$ têm redobrado seus esforços recentes de adaptação aos desafios impostos pela globalização, por meio de políticas ativas de promoção da "economia do conhecimento".

Para Wade (2010), é mais fácil sugerir que o Estado deve ter um papel mais ativo do que aquele admitido pela visão convencional aos moldes do Consenso de Washington, do que definir como estruturar e operacionalizar políticas desenvolvimentistas efetivas. A "política industrial em economias abertas" deveria ser capaz de combinar as "informações, perspectivas e objetivos do setor público com as do setor privado" de modo a se constituirem "as bases de um novo projeto de desenvolvimento nacional". ${ }^{30} \mathrm{O}$ desafio de combinar desenvolvimento com preservação do meio ambiente, os esforços de aumentar a produtividade

ferent from other economic models which rely primarily on natural resources or manpower, knowledge will be the primary engine of productivity and growth for the Korean economy. At its core, the Ministry strives to assemble traditional industrial know-how, cutting edge $R \& D$, and strong pro-business policies. MKE is a seamlessly integrated composition of former Ministries of Commerce, Industry and Energy; Information and Communication; and Science and Technology. This combination provides a vast array of experts to create synergies, spur innovation, and upgrade the nation's economy." Disponível em: <http://www. mke.go.kr/language/eng/about/responsibilities.jsp>. Acesso em: set. 2010.

27 "At the turn of the century, Singapore increased its focus on knowledge and innovationintensive activities. R\&D is now a cornerstone of the country's economic development..." Disponível em: <http://www.edb.gov.sg/edb/sg/en_uk/index/about_edb/our_history/ the_2000s.html $>$. Acesso em: out. 2010. Mais detalhes no site do Economic Development Board de Cingapura. Disponível em: <http://www.edb.gov.sg>.

${ }^{28}$ Desde 1953, o Council for Economic Planning and Development (CEPD) vem implentando planos nacionais de desenvolvimento, sendo o de 2009-2012 o mais recente. Suas prioridades são inovação tecnológica, desenvolvimento sustentável e inclusão social. "Third-Term Plan for National Development in the new century". Disponível em: $<$ http://www.cepd.gov.tw/encontent/m1.aspx?sNo=0011562>. Acesso em: set. 2010. Ver, também, o "2009 Industrial Development in Taiwan”. Disponível em: <http://www.moeaidb.gov.tw/external/view/en/about/index.html>. Acesso em: set. 2010.

${ }^{29}$ Ver o recente documento do METI (Ministry of Economy, Trade and Industry): 2011 Key Economic and Industrial Policies. Disponível em: <http://www.meti.go.jp/english/ aboutmeti/policy/2011policies.pdf > Acesso em: out. 2010.

${ }^{30}$ Tradução livre das expressões utilizadas por Wade (2010 p. 156). 
em vários setores tradicionais das economias menos desenvolvidas, a concorrência da produção manufatureira chinesa e os efeitos disruptivos dos padrões de produção e de consumo globais com a emergência das novas tecnologias de informação, robótica, nanotecnologia etc., são lembradas por Wade (2010) como fundamentais para justificar o "retorno" das políticas industriais.

O estabelecimento do "Estado Desenvolvimentista" do século XXI passaria pela capacidade de se criar sinergias entre o Estado e a sociedade em torno do objetivo maior que é o desenvolvimento. Este deveria estar acima dos interesses individuais imediatos. Portanto, o principal papel do Estado é o de organizar estruturas institucionais que viabilizem os objetivos desenvolvimentistas. Do ponto de vista histórico, o MITI japonês, o Council for Economic Planning and Development (CEPD) de Taiwan, o South Korea's Economic Planning Board e o Singapore's Economic Development Board estavam no topo de uma rede de agências governamentais e fóruns de interação com o setor privado, respondendo, em última instância, pelas estratégias nacionais de desenvolvimento. A partir destes exemplos e com o benefício da ampla revisão da literatura do PED, Wade (2010) conclui que há pelo menos quatro pré-condições para a emulação contemporânea dessas experiências, quais sejam: (I) a existência de equilíbrio nas relações entre o Estado e os grupos privados, onde estes, em troca do apoio estatal deveriam se comprometer a não tentar capturar o próprio Estado para a busca de facilidades individuais ${ }^{31}$; (II) a presença de uma burocracia estatal profissional, meritocrática e voltada para a realização dos objetivos da política desenvolvimentista; (III) a proteção das agências governamentais das pressões políticas voltadas à captura das quase-rendas criadas pelo Estado, de modo a preservar a eficiência econômica da políticas adotadas; e (IV) manter um volume baixo de recursos financeiros sob o controle discricionário dos burocratas responsáveis pela política desenvolvimentista; a estes caberia definir estratégias e instrumentos que, por sua vez, deveriam ser geridos por outros órgãos.

\footnotetext{
${ }^{31}$ Contraexemplos seriam o de economias asiáticas menos desenvolvidas, como Filipinas, em que as elites tradicionais se apropriavam do Estado impedindo a transformação produtiva e canalizando para si os benefícios das políticas públicas (Wade, 2010 p.158). Di Maio (2009) compara os exemplos de Ásia e América Latina, destacando que, neste último caso foi mais comum a captura do Estado pelas elites tradicionais.
} 


\section{Considerações finais}

O paradigma do Estado desenvolvimentista está intrinsecamente associado ao estudo das economias asiáticas mais bem-sucedidas em seus processos de transformação estrutural. Japão, Coreia do Sul, Taiwan e Cingapura, seguidas, com maior ou menor sucesso, por outras economias da região, adotaram estratégias pró-ativas de desenvolvimento, segundo os quais as políticas industriais tiveram um papel de centralidade. Entre os anos 1950 e 1980, o ambiente da Guerra Fria criou um vácuo para que a alternativa de um Estado "guia dos mercados", intermediária ao liberalismo e ao planejamento central (Johnson, 1982), fosse tolerada e, até mesmo, apoiada pelos EUA. Instrumentos protecionistas de apoio à indústria podiam ser utilizados sem maiores sanções da comunidade internacional.

Para a visão convencional, a especificidade asiática e a mudança no contexto histórico e institucional têm sido apontadas como obstáculos para que a experiência daqueles países possa ser emulada nestes tempos de globalização (World Bank, 1993; Noland; Pack, 2003; Pack; Saggi, 2006). Este argumento não encontra respaldo no PED. Em sua essência, esta perspectiva parte do estudo do exemplo asiático e avança para a constatação de que desde os primórdios da revolução industrial, as experiências mais relevantes de superação do atraso envolveram algum grau de ativismo estatal, expresso na busca consciente da construção de condições para a transformação das forças produtivas rumo aos parâmetros definidos pelas economias mais avançadas. Para o PED tal dinâmica de emulação não ocorre espontaneamente, a partir da exploração das vantagens comparativas estáticas derivadas da dotação prévia de fatores de produção. Cada circunstância histórica pode limitar "o que se pode fazer" e "como se pode fazer". Seguindo a sugestão de Rodrik (2009, 2010), Chang (2009) e Wade (2010), não se trata de discutir se a política industrial é necessária, mas sim, de como implementá-la com eficiência no mundo contemporâneo. No mundo pós-crise financeira global e com o aumento do poder econômico e político de economias emergentes repõe-se o desafio da ação estatal consciente para a construção do desenvolvimento.

Neste sentido, a principal contribuição da literatura do PED aqui resgatada é lembrar que um Estado desenvolvimentista é aquele que 
alinha suas políticas e instrumentos no sentido da busca de transformação qualitativa e quantitativa da base produtiva de um país. Tais políticas precisam ser (I) coerentes, à medida que não é suficiente haver políticas seletivas (a promoção de setores específicos) sem as horizontais (qualificação da infraestrutura, formação de recursos humanos etc.) e ambas podem não ser suficientes se os preços macroeconômicos retirarem incentivos para o incremento da produção, inovação e internacionalização; (II) efetivas, com mecanismos que induzam o setor privado na direção da eficiência produtiva e que evitem o rent-seeking; e (III) coordenadas entre as diversas instituições governamentais e não governamentais. Nesta perspectiva, o desenvolvimento deve ser uma prioridade que perpassa todas as esferas da sociedade e que se legitima à medida que é compartilhado por toda a sociedade. Mais do que um conjunto de políticas claramente definidas, o grande desafio parece continuar sendo o de como constituir um "Estado Desenvolvimentista". Conforme argumentado por Wade (2010), é mais fácil identificar essa necessidade do que implementar políticas desenvolvimentistas efetivas e eficazes.

\section{Referências}

AMSDEN, A. H. Asia's Next Giant: South Korea and late industrialization. New York: Oxford University Press, 1989.

. The Rise of "The Rest": challenges to the west from late-industrializing economies. Oxford University Press, 2001.

. Escape from Empire: the developing world's journey through heaven and hell. Cambridge: The MIT Press, 2007.

ARROW, J.K. Classificatory Notes on Production and Transmission of Technological Knowledge. The American Economic Review, v. 59, n. 2, may, p. 29-35, 1969.

BAILEY, D.; LENIHAN, H.; SINGH, A. Tiger, Tiger, Burning Bright? Industrial Policy Lessons from Ireland and East Asia for Small African Economies, ESRC Centre for Business Research - Working Papers n. 374, ESRC Centre for Business Research, 2008.

BALASSA, B. Growth Strategies in Semi-industrial Countries. Quarterly Journal of Economics, v.84, p.24-47, 1970.

. Outward Orientation. In CHENERY, H.; SRINIVASSAN, T. N. Handbook of Development Economics, vol II. Amsterdam: Elsevier Science Publishers, 1989.

BHAGWATI, J. (Editor). International Trade. Harmondsworth: Penguin Education, 1969. BIRDSALL, N.; JASPERSEN, F. Pathways to Growth: comparing East Asian and Latin America. Washington, DC: Inter-American Development Bank, 1997. 
CANUTO, O.; DUTZ, M. A.; REIS, J. G. Technological Learning: climbing a tall ladder. In: CANUTO, O.; GIUGALE, M (Editors). The Day After Tomorrow: a handbook on the future of economic policy in the developing world. Washington, DC: The World Bank, 2010.

CANUTO, O.; GIUGALE, M (Editors). The Day After Tomorrow: a handbook on the future of economic policy in the developing world. Washington, DC: The World Bank, 2010.

CEPAL. Progreso Técnico y Cambio Estructural en América Latina. Santiago de Chile: CEPAL, 2007.

CHANG, H. The Political Economy of Industrial Policy. London: The Macmilland Press, 1994.

. The East Asian Development Experience: the miracle, the crisis and the future. London: Zed Books, 2006.

. Industrial Policy: can we go beyond an unproductive confrontation? Annual World Bank Conference on Development Economics, Seoul, South Korea, June, 2009. Disponível em <http://siteresources.worldbank.org/INTABCDESK2009/Resources/Ha-Joon-Chang.pdf> . Acesso em: jul. 2010.

. Hamlet without the Prince of Denmark: how development has disappeared from today's 'development' discourse. In: KHAN, S.; CHRISTIANSEN, J. (Editors). Toward New Developmentalism: market as means rather than master. Routledge, 2010. (Draft Version 2009). Disponível em http://www.econ.cam.ac.uk/research/ econpapers.html?ep=pch741. Acesso em: jul. 2010.

CIMOLI, M.; DOSI, G.; STIGLITZ, J. The Future of Industrial Policy in the New Millennium: toward a knowledge-centered development agenda. In: CIMOLI, M.; DOSI, G.; STIGLITZ, J. (Editors). Industrial Policy and Development: the political economy of capabilities accumulation. Oxford University Press, 2009b. LEM Working Paper Series, n.19, sept., 2008. Disponível em: <http://lem.sssup.it>. Acesso em: jun. 2010.

.The Political Economy of Capabilities Accumulation: the past and future of policies for industrial development. In: CIMOLI, M.; DOSI, G.; STIGLITZ, J. (Editors). Industrial Policy and Development: the political economy of capabilities accumulation. Oxford University Press, 2009a. (LEM Working Paper Series, n.15, jul, 2008. Disponível em: <http://lem.sssup.it>. Acesso em: jun. 2010.

COMMISSION OF THE EUROPEAN COMMUNITIES. Mid-term Review of Industrial Policy: a contribution to the EU's growth and jobs strategy. Brussels, 2007 (Communication from the Commission to the European Parliament, the Council, the European Economic and Social Committee of Regions, COM (2007) 374 final).

DI MAIO, M. Industrial Policies in Developing Countries: history and perspectives. In: CIMOLI, M.; DOSI, G.; STIGLITZ, J. (Editors). Industrial Policy and Development: the political economy of capabilities accumulation. Oxford University Press, 2009. (Draft Version - Quaderno di Dipartimento n. 48, Maggio, Disponível em: <http://webhouse. unimc.it/economia/repo/quaderni/QDief48-2008.pdf>. Acesso em: jul. 2010.

DOSI, G.; FREEMAN, C.; FABIANI, S. The Process of Economic Development: Introducing Some Stylized Facts and Theories on Technologies, Firms and Institutions. Industrial and Corporate Change, v. 3, n. 1, nov., p. 1-45, 1994 
DOSI, G., NELSON, R. R. An Introduction to Evolutionary Theories in Economics. Journal of Evolutionary Economics, v.4, n.3, set., p. 243-268, 1994.

(THE) ECONOMIST. The Global Revival of Industrial Policy, august $5^{\text {th }}, 2010$.

EVANS, P. Embedded Autonomy: states and industrial transformation. Princeton: Princeton University Press, 1995.

HAQUE, I. Rethinking Industrial Policy. UNCTAD Discussion Paper 183, april. Geneva: United Nations Conference on Trade and Development, 2007.

IMF. World Economic Outlook, April. Washington, DC: International Monetary Fund, 2010.

JOHNSON, C. MITI and the Japanese Miracle. Stanford, CA: Stanford University Press, 1982.

JOMO, K. S. Growth after the Asian Crisis: what remains of the East Asian Model? G-24 Discussion Paper, n.10, march 2001.

. Developmental States in the face of globalization: Southeast Asia in comparative East Asian perspective. UNESCO, 2005. Disponível em <http://bibliotecavirtual. clacso.org.ar/ar/libros/reggen/pp07.pdf>. Acesso em: jul. 2010.

KRUEGER, A. O. The Political Economy of the Rent-Seeking Society. The American Economic Review, v. 64, n.3, Jun., p. 291-303, 1974.

KRUGMAN, P. The Rise and Fall of Development Economics, 1993 Disponível em: <http://web.mit.edu/krugman/www/dishpan.html>. Acesso em: set. 2010

LALL, S. Governments and Industrialization: the role of interventions in the 1990's. ECLAC-IDRC/UNU-INTECH Conference - Productivity, Technical Change, and National Innovation Systems in Latin America. Marbella, Chile, aug. 1995. (mimeo).

LIN, J. Y. New Structural Economics: a framework for rethinking development. Washington, DC: The World Bank, Policy Research Working Paper, n. 5197, february 2010.

LIN, J. Y.; MONGA, C. Growth Identification and Facilitation: the role of the State in the dynamics of structural change. Policy Research Working Paper, n. 3137, May. Washington, DC: The World Bank, 2010.

LITTLE, I.; SCITOVSKY, T.; SCOTT, M. Industry and Trade in Some Developing Countries: a comparative study. London: Oxford University Press, 1970.

NOLAND, M., PACK, H. The Asian Industrial Policy Experience: implications for Latin America. Working Paper Series n. 13, April. Washington, DC: Inter-American Development Bank, 2003.

PACK H., SAGGI, K. Is there a case for industrial policy? A critical survey. The World Bank Research Observer, v. 21, n.2, p. 267-297. Washington, DC: The World Bank, 2006.

PALMA, G. Gansos Voadores e Patos Vulneráveis: a diferença da liderança do Japão e dos Estados Unidos no desenvolvimento do Sudeste Asiático e da América Latina. In FIORI, J. L. (org.). O Poder Americano. Petrópolis, RJ: Editora Vozes, 2004.

PERES, W., PRIMI, A. Theory and Practice of Industrial Policy. Evidence from the Latin American Experience. Serie Desarrollo Productivo, n. 187, February. Santiago de Chile: CEPAL, 2009. 
REINERT, E. How Rich Countries Got Rich and Why Poor Countries Stay Poor. Public Affairs, 2007.

. Emulation versus Comparative Advantage: competing and complementary principles in the history of economic policy. In: CIMOLI, M., DOSI, G., STIGLITZ, J. (Editors). Industrial Policy and Development: the political economy of capabilities accumulation. Oxford University Press, 2009.

RODRIK, D. Getting Interventions Right: how South Korea and Taiwan grew rich. NBER Working Paper No. 4964. Dec., 1994.

RODRIK, D. Industrial Policy for the Twenty-First Century, CEPR Discussion Papers 4767, C.E.P.R. Discussion Papers, 2004.

. Industrial Development: Stylized Facts and Policies, 2006 In: United Nations, Industrial Development for the 21st Century, U.N. New York, 2007.

. Industrial Policy: Don’t Ask Why, Ask How, Middle East Development Journal (MEDJ), v. 1(01), p. 1-29, 2009.

. The Return of Industrial Policy, April. Disponível em <http://www.project-syndicate.org/commentary/rodrik42/English>. Acesso em: set. 2010.

SINGH, A. Globalisation, Openness and Economic Nationalism: Conceptual Issues and Asian Practise, MPRA Paper 24287, University Library of Munich, Germany, 2009.

SUZIGAN, W., FURTADO, J. Política Industrial e Desenvolvimento. Revista de Economia Política, São Paulo, v. 26, n. 2 (102), p. 163-185, abr.-jun., 2006.

UNCTAD. Trade and Development Report. Geneva: United Conference on Trade and Development (diversos anos).

WADE, R. Governing the Market: economic theory and the role of government in East Asian Industrialization. Princeton: Princeton University Press, 1990.

. After the Crisis: Industrial Policy and the Developmental State in Low-Income Countries. Global Policy, v. 1, Issue 2, May, p. 150-161, 2010.

WANG, M. The Political Economy of East Asia: striving for wealth and power. Washington, DC: CQ Press, 2008.

WOO-CUMINGS, M. The Developmental State. Cornell University Press, 1999.

WORLD BANK. The East Asian Miracle: economic growth and public policy. New York: Oxford University Press, 1993.

. Economic Growth in the 1990s: learning from a decade of reform. Washington, DC: World Bank, 2005.

. The Growth Report: strategies for sustained growth and inclusive development. Washington, DC: World Bank, 2008.

Bank, 2010.

Innovation Policy: a guide for developing countries. Washington, DC: World 


\section{Anexo estatístico}

Tabela 1. Indicadores Selecionados da Economia Mundial

\begin{tabular}{|c|c|c|c|c|c|c|c|}
\hline & \multicolumn{2}{|c|}{$\begin{array}{l}\text { Participação no PIB } \\
\text { Mundial (US\$ PPP) }\end{array}$} & \multicolumn{2}{|c|}{$\begin{array}{l}\text { Taxas de Crescimento } \\
\text { do PIB (\% ao ano - } \\
1980-2009)\end{array}$} & \multicolumn{3}{|c|}{$\begin{array}{l}\text { Participação nos Totais } \\
\text { Mundiais em } 2009 \text { (\%) }\end{array}$} \\
\hline & 1980 & 2009 & Média & $\begin{array}{l}\text { Desvio- } \\
\text {-Padrão }\end{array}$ & $\mathrm{PIB}$ & $\begin{array}{c}\text { Exportação } \\
\text { de Bens e } \\
\text { Serviços }\end{array}$ & População \\
\hline Países Desenvolvidos & 63,8 & 53,9 & 2,5 & 1,6 & 53,9 & 65,9 & 15,0 \\
\hline G7 & 51,0 & 41,0 & 2,3 & 1,6 & 41,0 & 36,3 & 10,9 \\
\hline NICs Asiáticos & 1,7 & 3,7 & 6,2 & 3,2 & 3,7 & 9,1 & 1,2 \\
\hline Países Emergentes e em Desenvolvimento & 36,2 & 46,1 & 4,3 & 1,8 & 46,1 & 34,1 & 85,0 \\
\hline África Subsaariana & 2,4 & 2,4 & 3,4 & 2,5 & 2,4 & 1,8 & 11,4 \\
\hline América Latina & 10,3 & 8,5 & 2,8 & 2,3 & 8,5 & 5,1 & 8,3 \\
\hline Ásia em Desenvolvimento & 7,2 & २2,5 & 7,3 & 1,6 & 22,5 & 14,4 & 52,5 \\
\hline Europa Emergente & 4,1 & 3,5 & 2,5 & 3,2 & 3,5 & 3,7 & 2,6 \\
\hline Oriente Médio e Norte da África & 4,6 & 5,0 & 3,4 & 2,4 & 5,0 & 5,8 & 6,0 \\
\hline \multicolumn{8}{|l|}{ Memória } \\
\hline Ásia em Desenvolvimento + NICs Asiáticos & 8,9 & 26,2 & nd & nd & 26,2 & 23,5 & 53,7 \\
\hline
\end{tabular}

Fonte: Elaboração própria com base em IMF World Economic Outlook Database, April 2010. Disponível em: http://www.imf.org/external/pubs/ft/weo/201001/weodata/index.aspx.Acesso em ago.2010.

(*) Para ver os países que compõem cada agregado regional, consultar a fonte.

Gráfico 1. Participação da Ásia e América Latina na Renda* Mundial, 1962-2008 (\%)

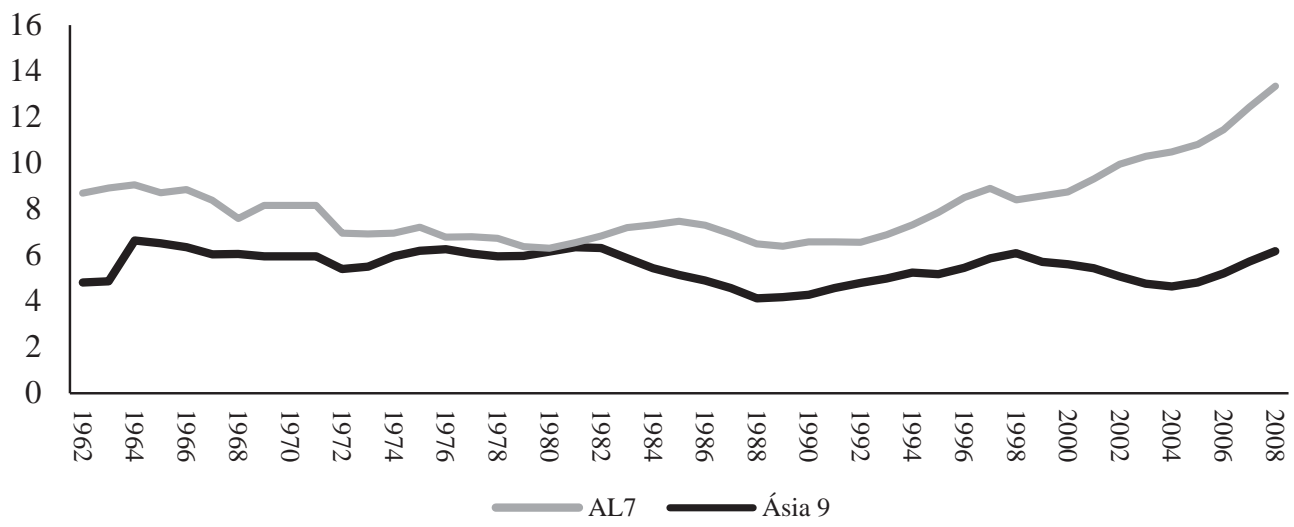

Fonte: Elaboração Própria com base nos dados do World Development Indicators 2009. Disponível em: http://data.worldbank.org/. Acesso em agosto de 2010. Nota: AL 7 = Argentina, Brasil, Chile, Colômbia, México, Peru e Venezuela. Ásia 9 = Coreia do Sul, Cingapura, Hong Kong, Malásia, Indonésia, Filipinas, Tailândia, China e Índia.

(*) GNI, Método Atlas em dólares correntes 


\section{Gráfico 2. Participação da Ásia (incl. Japão) e América Latina}

na Renda Mundial(*), 1962-2008 (\%)

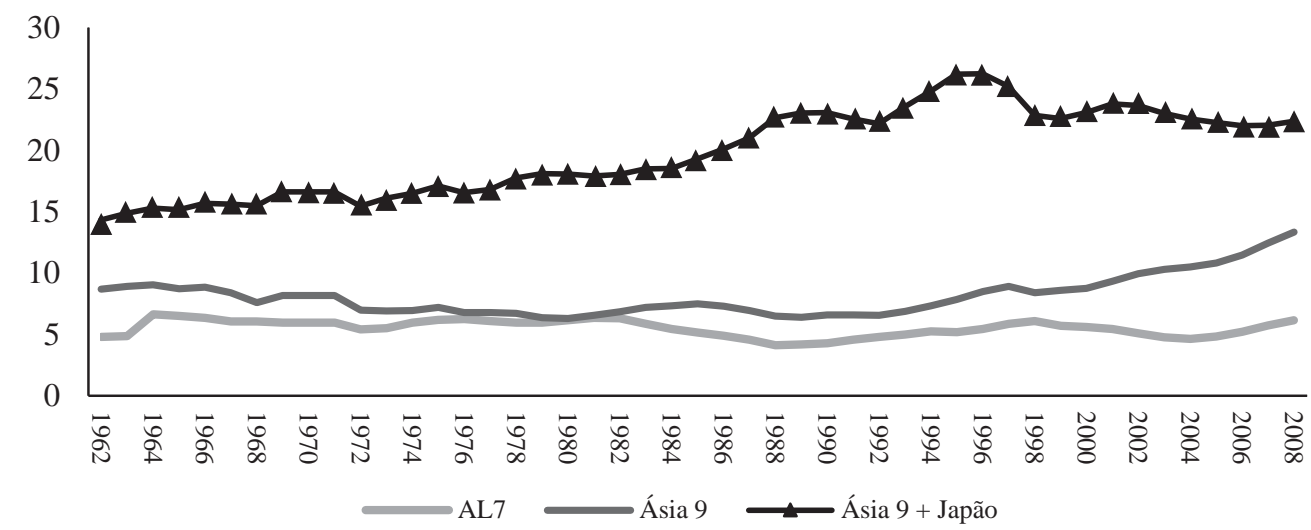

Fonte: Elaboração Própria com base nos dados do World Development Indicators 2009. Disponível em: http://data.worldbank.org/. Acesso em agosto de 2010. AL 7 = Argentina, Brasil, Chile, Colômbia, México, Peru e Venezuela. Ásia 9 = Coreia do Sul, Cingapura, Hong Kong, Malásia, Indonésia, Filipinas, Tailândia, China e Índia.

$\left(^{*}\right)$ GNI, Método Atlas em dólares correntes

Gráfico 3. Participação de Economias Selecionadas nas Exportações Mundiais de Mercadorias, 1948-2009

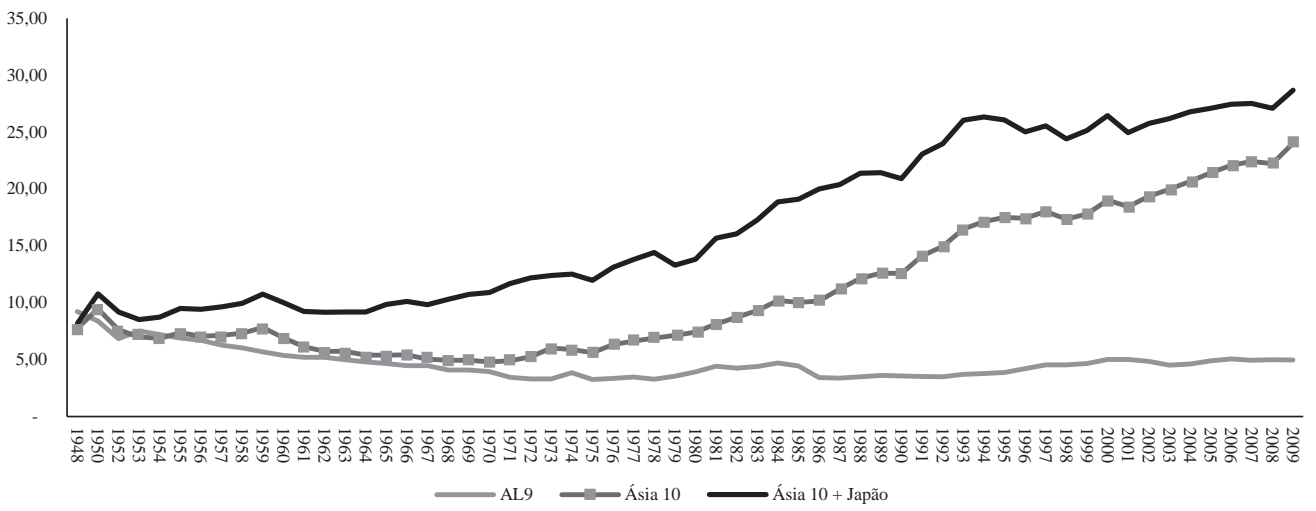

Fonte: WTO Time Series on International Trade. Disponível em: <http://www.wto.org/english/ res_e/statis_e/statis_e.htm> Acesso em: ago. 2010.

AL 9 = Argentina, Bolívia, Brasil, Chile, Colômbia, México, Peru, Uruguai e Venezuela. Ásia $10=$ Coreia do Sul, Taiwan, Cingapura, Hong Kong, Malásia, Indonésia, Filipinas, Tailândia, China e Índia 
Tabela 2. Investimento Direto Externo* em Economias Selecionas, 1980-2009

\begin{tabular}{|c|c|c|c|c|c|c|c|c|}
\hline & \multicolumn{3}{|c|}{ Estoque de IDE - US\$ Bilhões } & \multicolumn{3}{|c|}{ Participação no Estoque de IDE (\%) } & \multicolumn{2}{|c|}{ Estoque de IDE/PIB (\%) } \\
\hline & 1980 & 1990 & 2009 & 1980 & 1990 & 2009 & 1980 & 2009 \\
\hline Mundo & 700.277 & 2.081 .782 & 17.743 .408 & 100,00 & 100,00 & 100,00 & 6,62 & 30,54 \\
\hline I. Países Desenvolvidos & 401.633 & 1.555 .605 & 12.352.514 & 57,35 & 74,72 & 69,62 & 5,07 & 31,81 \\
\hline Alemanha ${ }^{* \ldots *}$ & 36.630 & 111.231 & 701.643 & 5,23 & 5,34 & 3,95 & 3,98 & 21,02 \\
\hline EUA & 83.046 & 539.601 & 3.120 .583 & 11,86 & 25,92 & 17,59 & 2,98 & 22,61 \\
\hline Japão & 3.270 & 9.850 & 200.141 & 0,47 & 0,47 & 1,13 & 0,31 & 3,93 \\
\hline $\begin{array}{l}\text { II. Países em } \\
\text { Desenvolvimento }\end{array}$ & 298.644 & 524.526 & 4.893.490 & 42,65 & 25,20 & 27,58 & 11,58 & 27,88 \\
\hline África & 41.097 & 60.675 & 514.759 & 5,87 & 2,91 & 2,90 & 9,57 & 35,79 \\
\hline América Latina & 41.789 & 111.377 & 1.472 .744 & 5,97 & $\mathbf{5 , 3 5}$ & 8,30 & 5,25 & 30,95 \\
\hline Argentina & 2.083 & 9.085 & 80.996 & 0,30 & 0,44 & 0,46 & 2,76 & 25,87 \\
\hline Brasil & 17.480 & 37.143 & 400.808 & 2,50 & 1,78 & 2,26 & 7,68 & 26,19 \\
\hline Chile & 10.847 & 16.107 & 121.640 & 1,55 & 0,77 & 0,69 & 36,79 & 75,01 \\
\hline Colômbia & 1.061 & 3.500 & 74.092 & 0,15 & 0,17 & 0,42 & 2,39 & 32,44 \\
\hline México & 2.984 & २2.424 & 309.523 & 0,43 & 1,08 & 1,74 & 1,47 & 35,65 \\
\hline Ásia & 214.236 & 349.638 & 2.893 .718 & 30,59 & 16,80 & 16,31 & 15,92 & 25,75 \\
\hline Hong Kong & 177.755 & 201.653 & 912.166 & 25,38 & 9,69 & 5,14 & 616,82 & 431,99 \\
\hline Ásia excl. Hong Kong & 36.480 & 147.985 & 1.981 .612 & 5,21 & 7,11 & 11,17 & nd & nd \\
\hline China & 1.074 & 20.691 & 473.083 & 0,15 & 0,99 & 2,67 & 0,35 & 10,07 \\
\hline Cingapura & 5.351 & 30.468 & 343.599 & 0,76 & 1,46 & 1,94 & 45,66 & २००,७२ \\
\hline Coréia do Sul & 1.139 & 5.186 & 110.770 & 0,16 & 0,25 & 0,62 & 1,71 & 13,34 \\
\hline Filipinas & 914 & 4.528 & 23.559 & 0,13 & 0,22 & 0,13 & 2,82 & 14,54 \\
\hline Índia & 452 & 1.657 & 163.959 & 0,06 & 0,08 & 0,92 & 0,24 & 13,31 \\
\hline Indonésia & 4.560 & 8.733 & 72.841 & 0,65 & 0,42 & 0,41 & 5,73 & 13,47 \\
\hline Malásia & 5.169 & 10.318 & 74.643 & 0,74 & 0,50 & 0,42 & 20,33 & 39,01 \\
\hline Tailândia & 981 & 8.242 & 99.000 & 0,14 & 0,40 & 0,56 & 3,03 & 36,22 \\
\hline Taiwan & 2.405 & 9.735 & 48.261 & 0,34 & 0,47 & 0,27 & 5,69 & 13,11 \\
\hline
\end{tabular}

Fonte: UNCTAD FDI On Line Database. Disponível em: $<$ http//stats.unctad.org/fdi/ReportFolders. aspx?sCS_referer=\&sCS_ChosenLang=em>. Acesso em: ago. 2010.

$\left.{ }^{*}\right)$ Referente às entradas de IDE.

(**) Para 1980 os dados são da RFA (ex-Alemanha Ocidental)

${ }^{(* * *)}$ A primeira informação se refere ao ano de 1982. 
Gráfico 4. Exportações de Produtos de Alta Tecnologia* em Economias Selecionadas, 1988-2008 (\% do total das exportações de manufaturas)

Alemanha

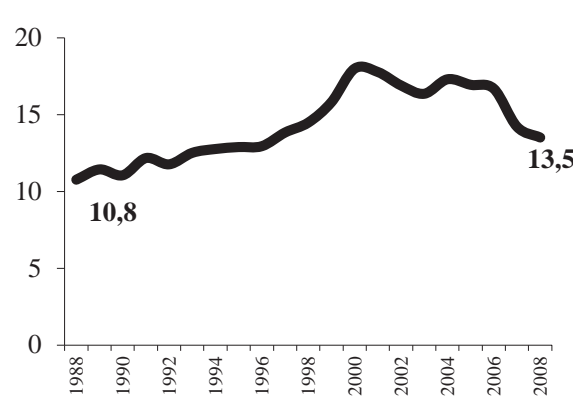

Argentina

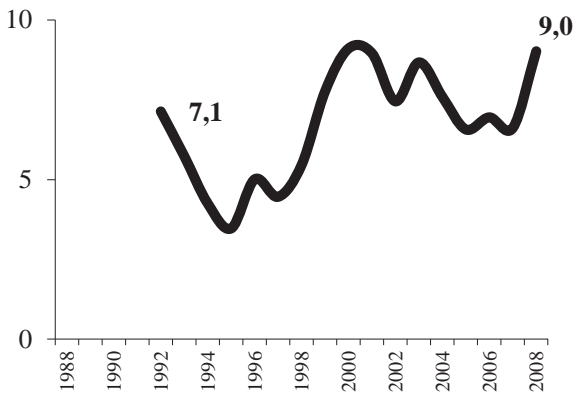

Brasil

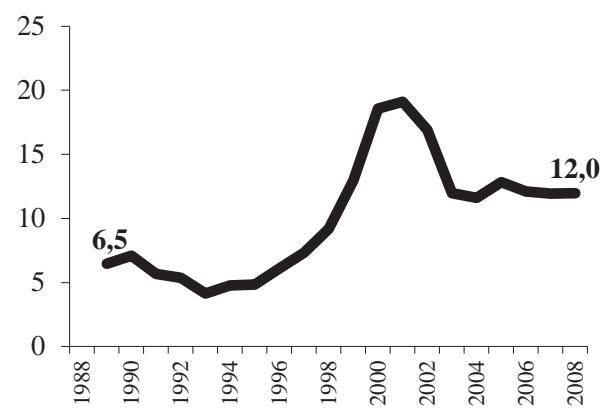

China

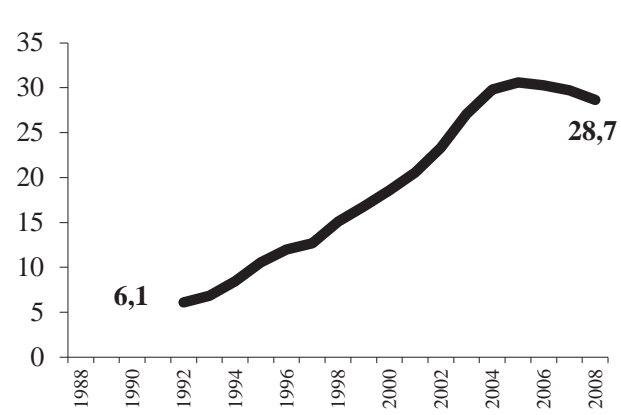

Chile

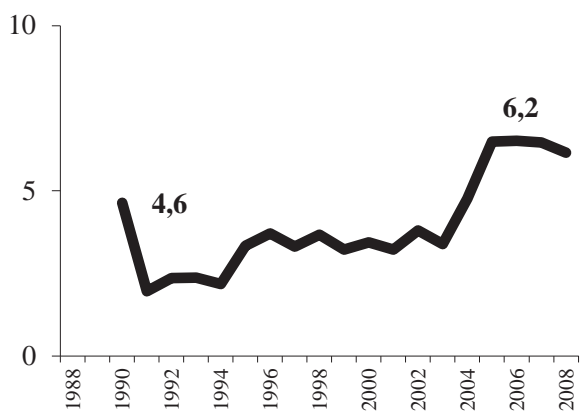

Cingapura

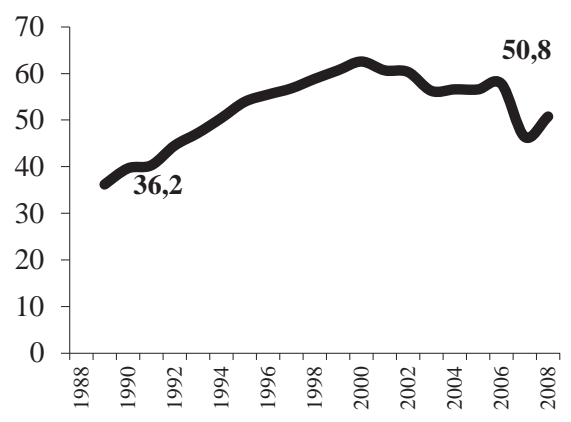


Coréia do Sul

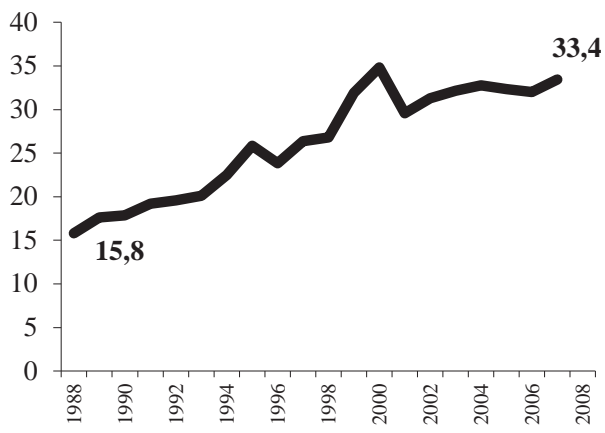

Filipinas

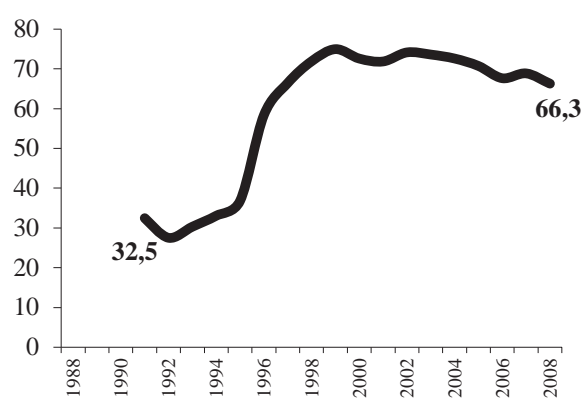

Indonésia

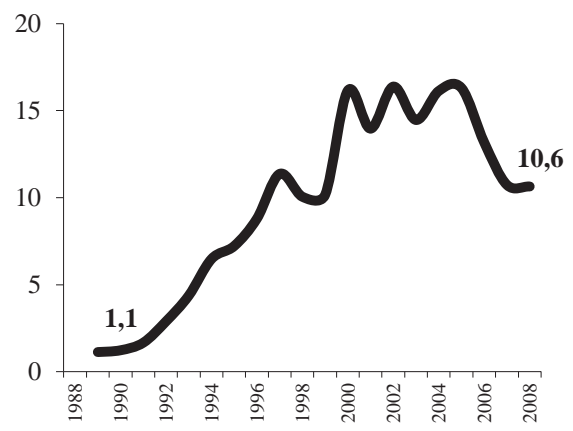

EUA

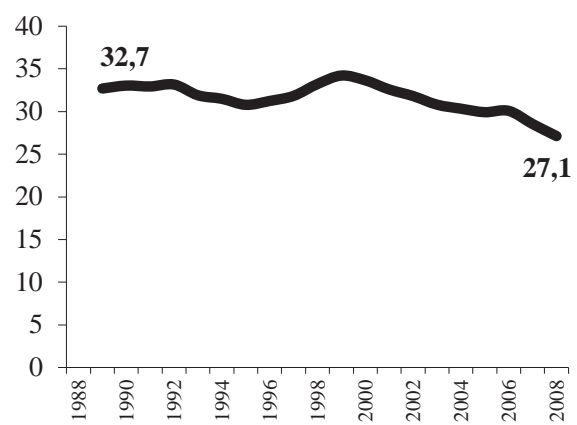
Índia

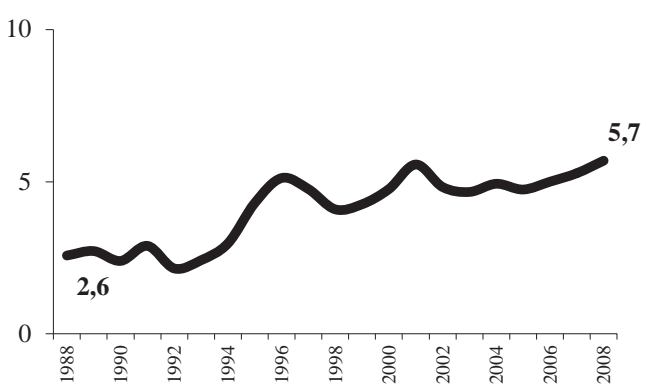

Japão

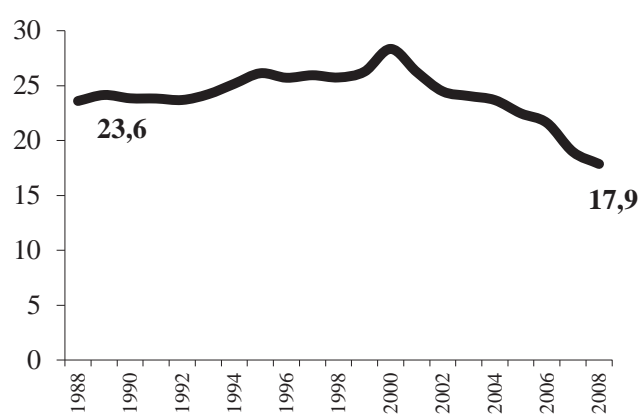


Malásia

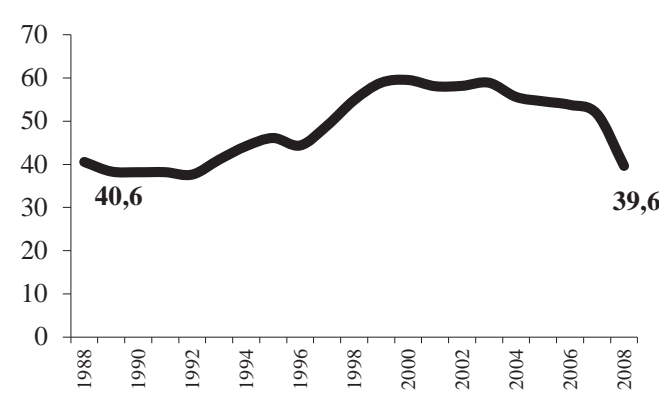

México

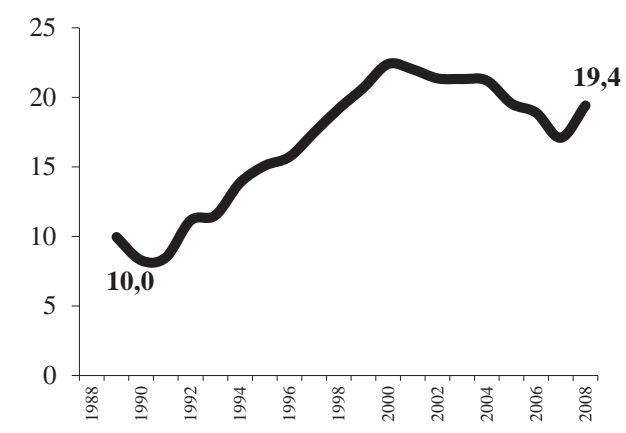

Tailândia

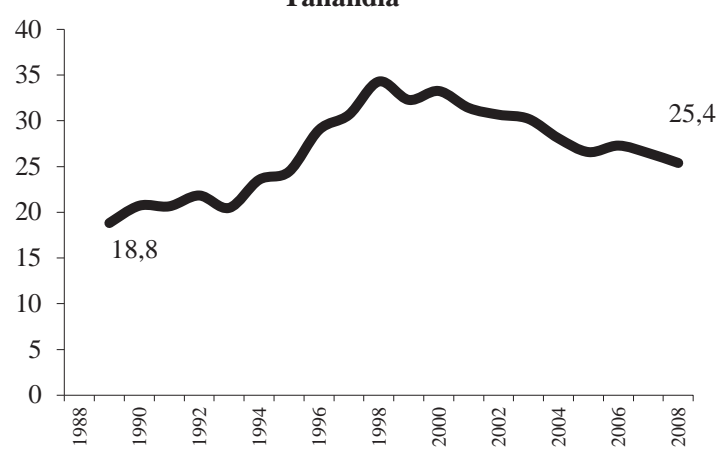

Fonte: Elaboração Própria com base nos dados do World Development Indicators 2009. Disponível em: $<$ http://data.worldbank.org/>. Acesso em: ago. 2010.

(*) São produtos intensivos em pesquisa e desenvolvimento tais como produtos aeroespaciais, computadores, produtos farmaêuticos, instrumentos científicos e maquinaria elétrica. 
Gráfico 5. Evolução da Renda Per Capita de Economias Selecionadas, 1950-2007 (valores correntes - EUA $=100$
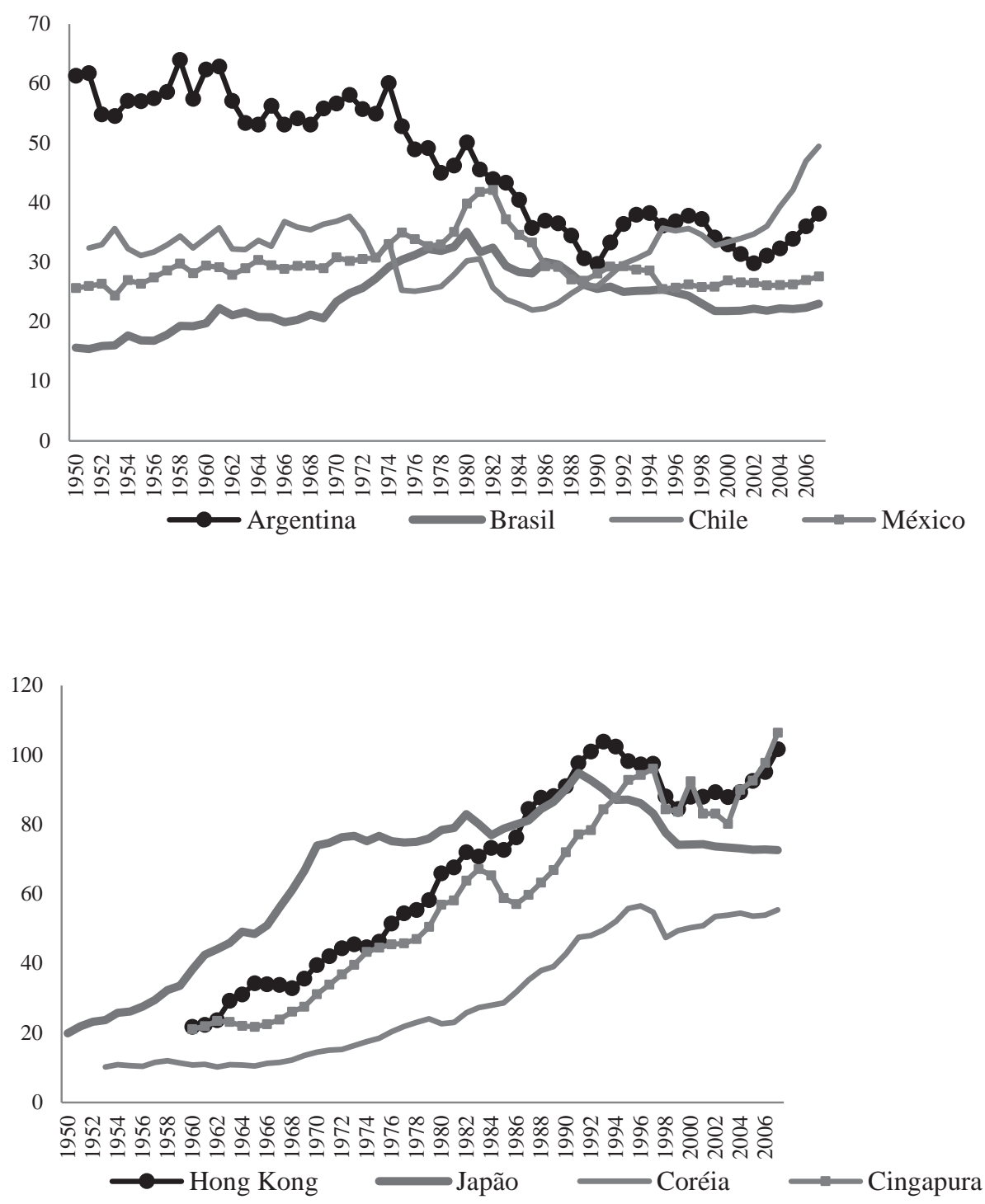


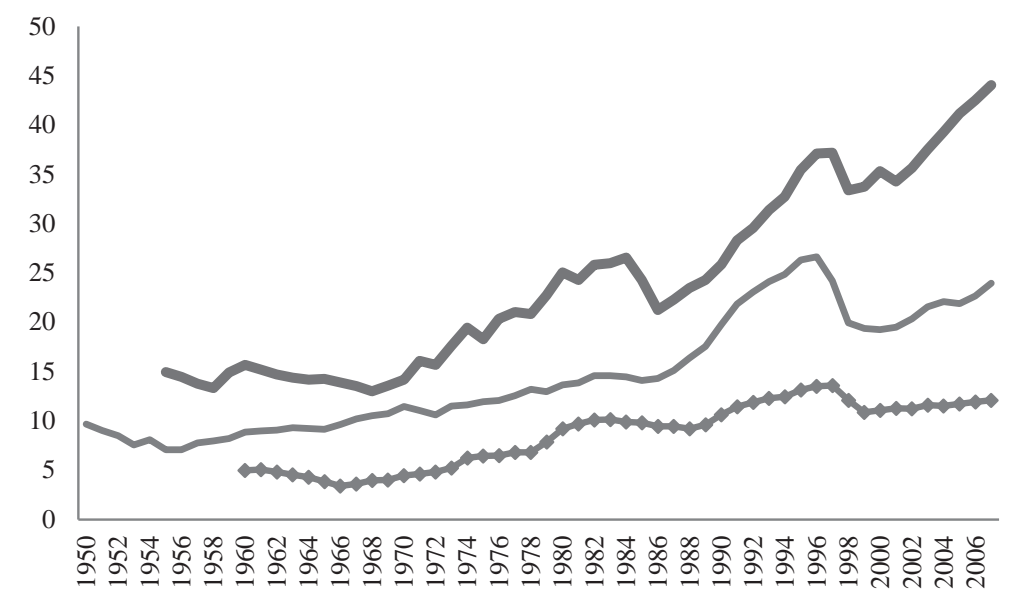

$\longrightarrow$ Indonésia $\rightleftharpoons$ Malásia Tailândia

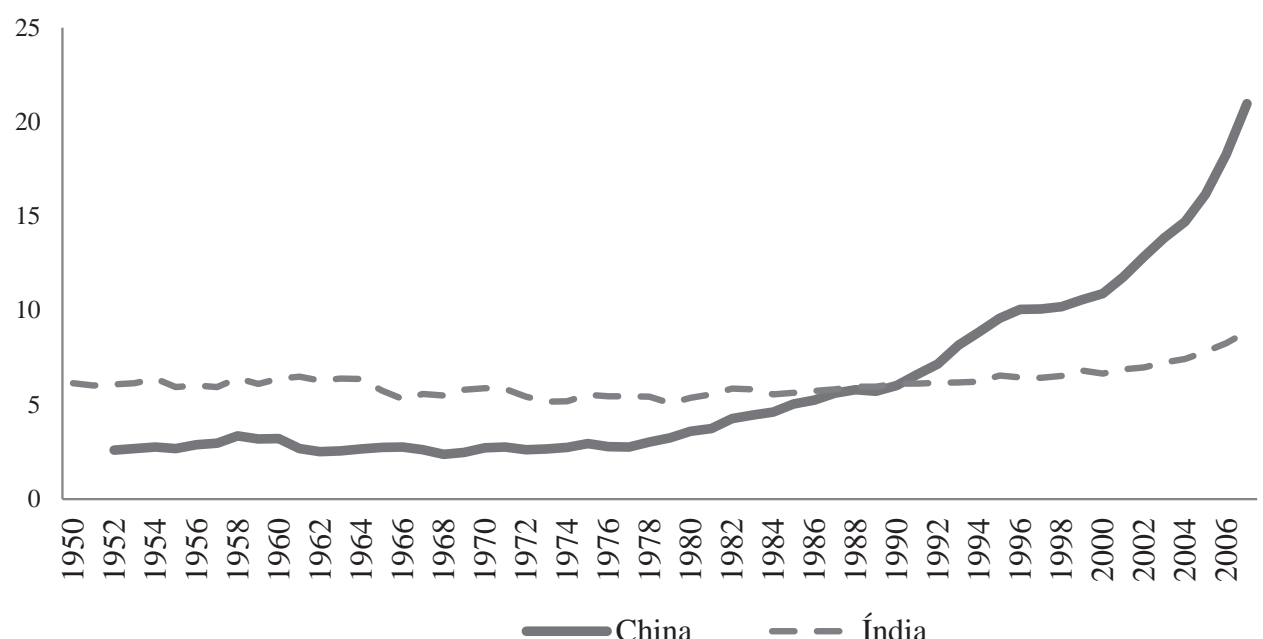

Fonte: Penn World Tables, 6.3. Disponível em: <http://pwt.econ.upenn.edu/php_site/pwt63_form. php >. Acesso em: set. 2010. 
Tabela 3. Comércio Internacional, Investimentos e População Rural em Economias Selecionadas, 1960-2008

\begin{tabular}{|c|c|c|c|c|c|c|c|c|c|c|c|c|}
\hline & \multirow{2}{*}{\multicolumn{3}{|c|}{$\begin{array}{c}\text { População Rural } \\
\text { (\% do total) }\end{array}$}} & \multicolumn{6}{|c|}{ Comércio Internacional de Bens e Serviços* (\% do PIB) } & \multirow{2}{*}{\multicolumn{3}{|c|}{$\begin{array}{l}\text { Formação Bruta de Capital } \\
\text { (\% do PIB) }\end{array}$}} \\
\hline & & & & \multicolumn{3}{|c|}{ Importações } & \multicolumn{3}{|c|}{ Exportações } & & & \\
\hline & 1960 & 1980 & 2008 & 1960s & 1980s & 2000s & 1960s & 1980s & 2000s & 1960s & $1980 \mathrm{~s}$ & २०००s \\
\hline \multicolumn{13}{|c|}{ I. América Latina } \\
\hline Argentina & 26,4 & 17,1 & 8,0 & 6,0 & 6,2 & 16,8 & 6,3 & 9,3 & 23,5 & 22,4 & 18,8 & 19,1 \\
\hline Brasil & 55,1 & 32,6 & 14,4 & 6,5 & 7,3 & 12,5 & 6,7 & 10,1 & 14,4 & 19,7 & 20,7 & 17,1 \\
\hline Chile & 32,2 & 18,8 & 11,6 & 13,8 & 26,2 & 33,2 & 13,7 & 27,5 & 40,5 & 18,1 & 18,9 & 21,7 \\
\hline Colômbia & 55,0 & 37,9 & 25,5 & 13,2 & 13,6 & 21,4 & 12,5 & 15,0 & 17,1 & 19,3 & 19,4 & 21,0 \\
\hline México & 49,2 & 33,7 & २2,8 & 9,6 & 13,7 & 29,0 & 7,7 & 17,2 & 27,3 & 19,3 & 21,9 & 23,8 \\
\hline Peru & 53,2 & 35,4 & 28,6 & 19,9 & 16,7 & 19,8 & 18,2 & 16,7 & २2,6 & 32,6 & 24,5 & 20,2 \\
\hline Venezuela & 38,4 & 20,8 & 6,7 & 15,9 & 20,7 & 20,0 & 25,3 & 25,5 & 32,6 & 25,3 & 19,8 & 23,3 \\
\hline \multicolumn{13}{|c|}{ II. Ásia } \\
\hline China & 84,0 & 80,4 & 56,9 & 2,7 & 14,0 & 28,1 & 2,6 & 13,7 & 33,1 & 20,3 & 36,1 & 41,8 \\
\hline Cingapura & 0,0 & 0,0 & 0,0 & nd & nd & 196,4 & nd & nd & २२०,७ & २२,७ & 41,6 & २२,५ \\
\hline Coréia do Sul & 72,3 & 43,3 & 18,5 & 19,3 & 32,3 & 38,0 & 8,9 & 33,5 & 39,9 & 20,3 & 31,0 & 29,8 \\
\hline Filipinas & 69,7 & 62,5 & 35,1 & 18,5 & 26,7 & 49,2 & 17,9 & 25,1 & 46,8 & 22,2 & 21,7 & 16,2 \\
\hline Hong Kong & 14,8 & 8,5 & 0,0 & 80,5 & 104,0 & 174,7 & 78,5 & 110,8 & 184,3 & 25,4 & 27,0 & 21,9 \\
\hline Índia & 82,1 & 76,9 & 70,5 & 5,5 & 7,9 & 20,7 & 4,0 & 6,1 & 18,3 & 15,4 & 22,4 & 32,2 \\
\hline Indonésia & 85,4 & 77,9 & 48,5 & 12,5 & 22,8 & 27,2 & 10,3 & 24,5 & 32,3 & 10,4 & 29,2 & 24,6 \\
\hline Malásia & 73,4 & 58,0 & 29,6 & 37,9 & 56,6 & 92,2 & 41,7 & 59,0 & 112,2 & 17,9 & 28,3 & 22,6 \\
\hline Tailândia & 80,3 & 73,2 & 66,7 & 18,4 & 30,0 & 65,7 & 16,2 & 26,9 & 70,4 & 21,5 & 30,7 & 26,8 \\
\hline \multicolumn{13}{|c|}{ III. Economias Avançadas } \\
\hline Alemanha & 28,6 & 27,2 & 26,4 & 9,5 & 10,4 & 12,2 & 16,4 & 23,3 & 40,7 & 30,5 & २२,१ & 17,9 \\
\hline EUA & 30,0 & 26,3 & 18,3 & 17,9 & 24,9 & 35,7 & 5,3 & 8,4 & 10,5 & 19,2 & 19,4 & 18,8 \\
\hline Japão & 56,9 & 40,4 & 33,5 & 4,7 & 10,3 & 15,4 & 9,9 & 12,5 & 13,6 & 35,8 & 30,2 & 23,6 \\
\hline
\end{tabular}

Fonte: World Development Indicators on Line, World Bank. Disponível em: <http://data.worldbank.org/ topic>. Acesso em: ago. 2010.

(*) Foram calculadas as médias em cada década. Nos anos 1960 há, em alguns casos, lacunas de informações. 
Tabela 4. Distribuição Setorial do PIB em Economias Selecionadas, 1960-2008* (\%)

\begin{tabular}{|c|c|c|c|c|c|c|c|c|c|}
\hline & \multicolumn{3}{|c|}{ Agricultura } & \multicolumn{3}{|c|}{ Indústria } & \multicolumn{3}{|c|}{ Serviços } \\
\hline & $1960 \mathrm{~s}$ & 1980s & 2000s & $1960 \mathrm{~s}$ & 1980s & 2000s & 1960s & 1980s & $2000 \mathrm{~s}$ \\
\hline \multicolumn{10}{|c|}{ I. América Latina } \\
\hline Argentina & 10,3 & 8,3 & 9,2 & 47,0 & 39,4 & 33,3 & 42,7 & 52,3 & 57,5 \\
\hline Brasil & 16,0 & 10,2 & 6,3 & 36,3 & 44,0 & 28,3 & 47,7 & 45,8 & 65,4 \\
\hline Chile & 8,4 & 7,7 & 4,6 & 40,1 & 39,1 & 41,9 & 51,5 & 53,2 & 53,5 \\
\hline Colômbia & 27,9 & 18,1 & 9,8 & 27,0 & 35,2 & 33,0 & 45,1 & 46,7 & 57,2 \\
\hline México & 12,3 & 8,9 & 3,9 & 28,7 & 33,5 & 32,9 & 59,0 & 57,7 & 63,2 \\
\hline Peru & 18,8 & 9,7 & 7,4 & 30,3 & 31,6 & 33,5 & 50,8 & 58,8 & 59,0 \\
\hline Venezuela & 5,5 & 5,9 & 4,3 & 39,6 & 49,6 & 52,1 & 54,2 & 44,4 & 43,6 \\
\hline \multicolumn{10}{|c|}{ II. Ásia } \\
\hline China & 38,4 & 29,1 & 12,5 & 34,7 & 43,6 & 47,0 & 26,8 & 27,3 & 40,5 \\
\hline Cingapura & nd & 0,9 & 0,1 & nd & 36,9 & 31,8 & nd & 62,2 & 68,1 \\
\hline $\begin{array}{l}\text { Coréia do } \\
\text { Sul }\end{array}$ & 31,0 & 12,7 & 3,5 & 22,3 & 39,7 & 37,1 & 46,8 & 47,6 & 59,4 \\
\hline Filipinas & 27,8 & 23,5 & 14,7 & 31,2 & 36,4 & 31,7 & 41,0 & 40,1 & 53,6 \\
\hline $\begin{array}{l}\text { Hong } \\
\text { Kong }\end{array}$ & nd & 0,5 & 0,1 & nd & 28,6 & 10,1 & nd & 71,0 & 89,8 \\
\hline Índia & 42,5 & 31,3 & 19,6 & 20,3 & 26,2 & 27,8 & 37,2 & 42,5 & 52,5 \\
\hline Indonésia & 50,9 & 22,7 & 14,3 & 14,8 & 37,9 & 46,0 & 34,3 & 39,4 & 39,7 \\
\hline Malásia & 30,7 & 19,6 & 4,4 & 25,8 & 39,1 & 47,6 & 43,4 & 41,3 & 47,9 \\
\hline Tailândia & 31,1 & 16,8 & 10,3 & २2,8 & 32,8 & 43,6 & 46,0 & 50,3 & 46,1 \\
\hline \multicolumn{10}{|c|}{ III. Economias Avançadas } \\
\hline Alemanha & 6,4 & 3,2 & 1,6 & 46,0 & 39,9 & 30,3 & 47,6 & 57,0 & 68,1 \\
\hline EUA & 3,7 & 2,0 & 1,0 & 48,1 & 38,7 & 29,5 & 48,2 & 59,3 & 69,5 \\
\hline Japão & 3,5 & 2,4 & 1,2 & 35,2 & 30,6 & 22,3 & 61,2 & 67,0 & 76,5 \\
\hline
\end{tabular}

Fonte: World Development Indicators on Line, World Bank. Disponível em: <http://data.worldbank.org/ topic >. Acesso em: ago. 2010.

(*) Foram calculadas as médias em cada década. Nos anos 1960 há, em alguns casos, lacunas de informações. 
Tabela 5. Evolução do Índice de Desenvolvimento Humano (IDH) em Países Selecionados, 1980-2007

\begin{tabular}{|c|c|c|c|}
\hline & \multirow[t]{2}{*}{ Ranking 2007} & \multicolumn{2}{|c|}{ IDH } \\
\hline & & 1980 & 2007 \\
\hline Noruega & 1 & 0,900 & 0,971 \\
\hline Japão & 10 & 0,887 & 0,960 \\
\hline EUA & 13 & 0,894 & 0,956 \\
\hline Singapore & 23 & 0,785 & 0,944 \\
\hline Hong Kong & 24 & nd & 0,944 \\
\hline Coréia do Sul & 26 & 0,722 & 0,937 \\
\hline Chile & 44 & 0,748 & 0,878 \\
\hline Argentina & 49 & 0,793 & 0,866 \\
\hline México & 53 & 0,756 & 0,854 \\
\hline Venezuela & 58 & 0,765 & 0,844 \\
\hline Malásia & 66 & 0,666 & 0,829 \\
\hline Rússia & 71 & nd & 0,817 \\
\hline Brasil & 75 & 0,685 & 0,813 \\
\hline Colômbia & 77 & 0,688 & 0,807 \\
\hline Peru & 78 & 0,687 & 0,806 \\
\hline Tailândia & 87 & 0,658 & 0,783 \\
\hline China & 92 & 0,533 & 0,772 \\
\hline Filipinas & 105 & 0,652 & 0,751 \\
\hline Indonésia & 111 & 0,522 & 0,734 \\
\hline Índia & 134 & 0,427 & 0,612 \\
\hline
\end{tabular}

Fonte: Human Development Report 2009. Disponível em: < htpp://hdr.undp.org/en/statistics/>. Acesso em: set. 2010. 


\section{Gráfico 6. Gastos em P\&D em Economias Selecionadas}

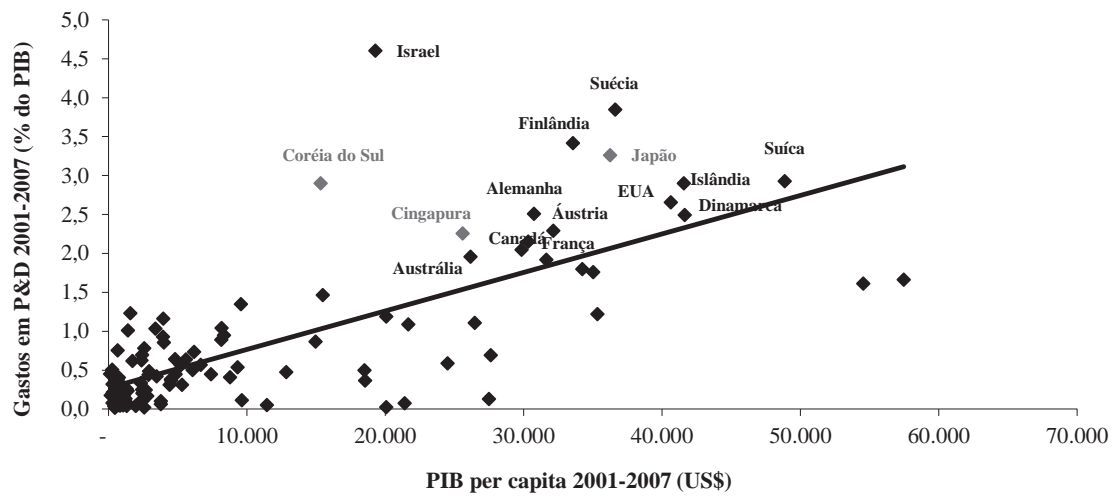

Argentina: US\$ 4.849; $0,45 \%$

Chile: US\$ $5.591 ; 0,64 \%$

Brasil: US\$ 3.933; 0,93\%

China: US\$ $1.576 ; 1,23 \%$

Indonésia: US\$ $1.040 ; 0,05 \%$

Índia: US\$ 657; $0,75 \%$

México: US\$ 7.397; 0,45\%

Fonte: World Development Indicators on Line, World Bank. Disponível em: <http://data.worldbank.org/ topic> Acesso em: ago. 2010.

\section{Gráfico 7. Exportação de ICT* em Economias Selecionadas, 2006-2008 (\% do total das exportações)}

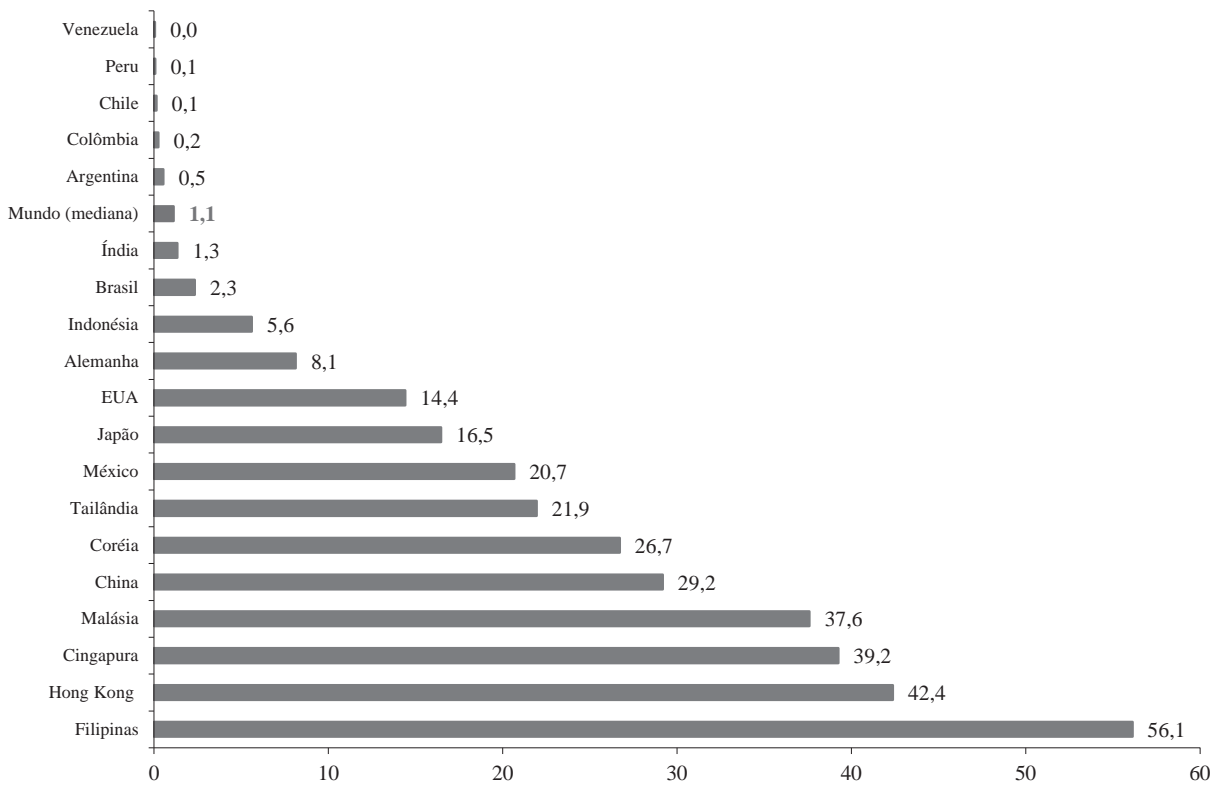

Fonte: World Development Indicators on Line, World Bank. Disponível em: <http://data.worldbank.org/ topic> Acesso em: ago. de 2010. (*)Information and Communication Technology: são bens de tecnologia de informação e comunicações, ou seja, telecomunicões, áudio, vídeo, computadores e equipamentos relacionados, componentes eletrônicos, dentre outros. Exclui softwares. 


\section{Gráfico 8. Gastos em Tecnologias de Informação e Comunicação* em Economias Selecionadas (\% do PIB, média 2003-2008)}

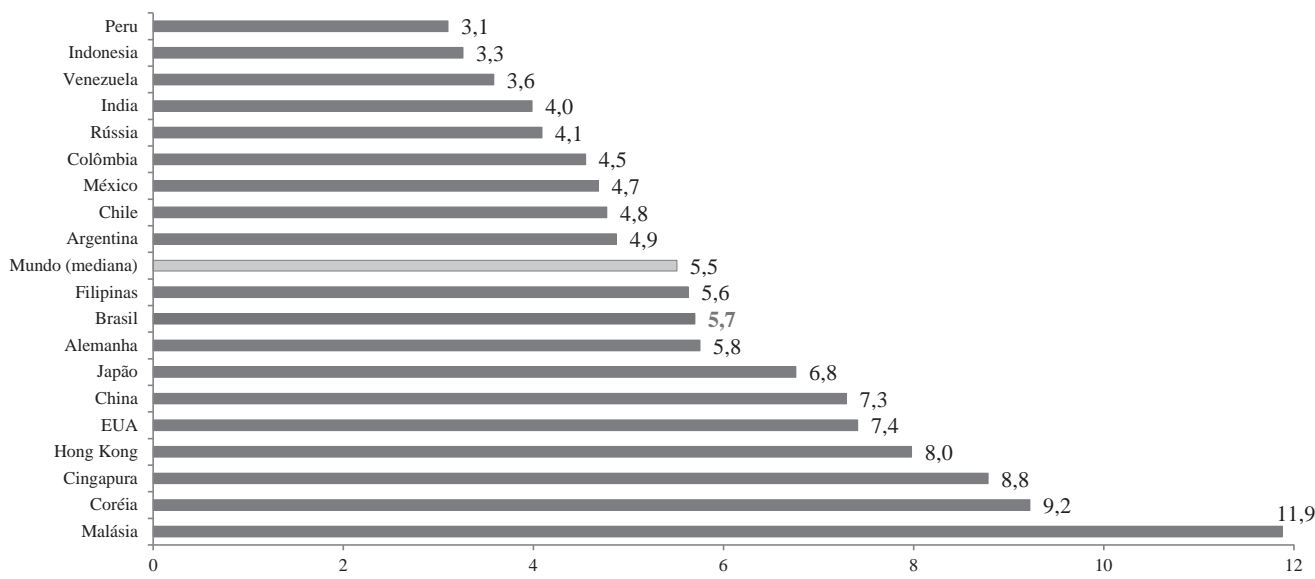

Fonte: World Development Indicators on Line, World Bank. Disponível em: <http://data.worldbank.org/ topic > Acesso em: ago. 2010. Incluindo equipamentos de informática e softwares, serviços de computação e comunicação e outros gastos associados a estas tecnologias. $\left({ }^{*}\right)$. 
Gráfico 9. Usuários de Internet em Países Selecionados, 2008 ( por 1.000 habitantes)

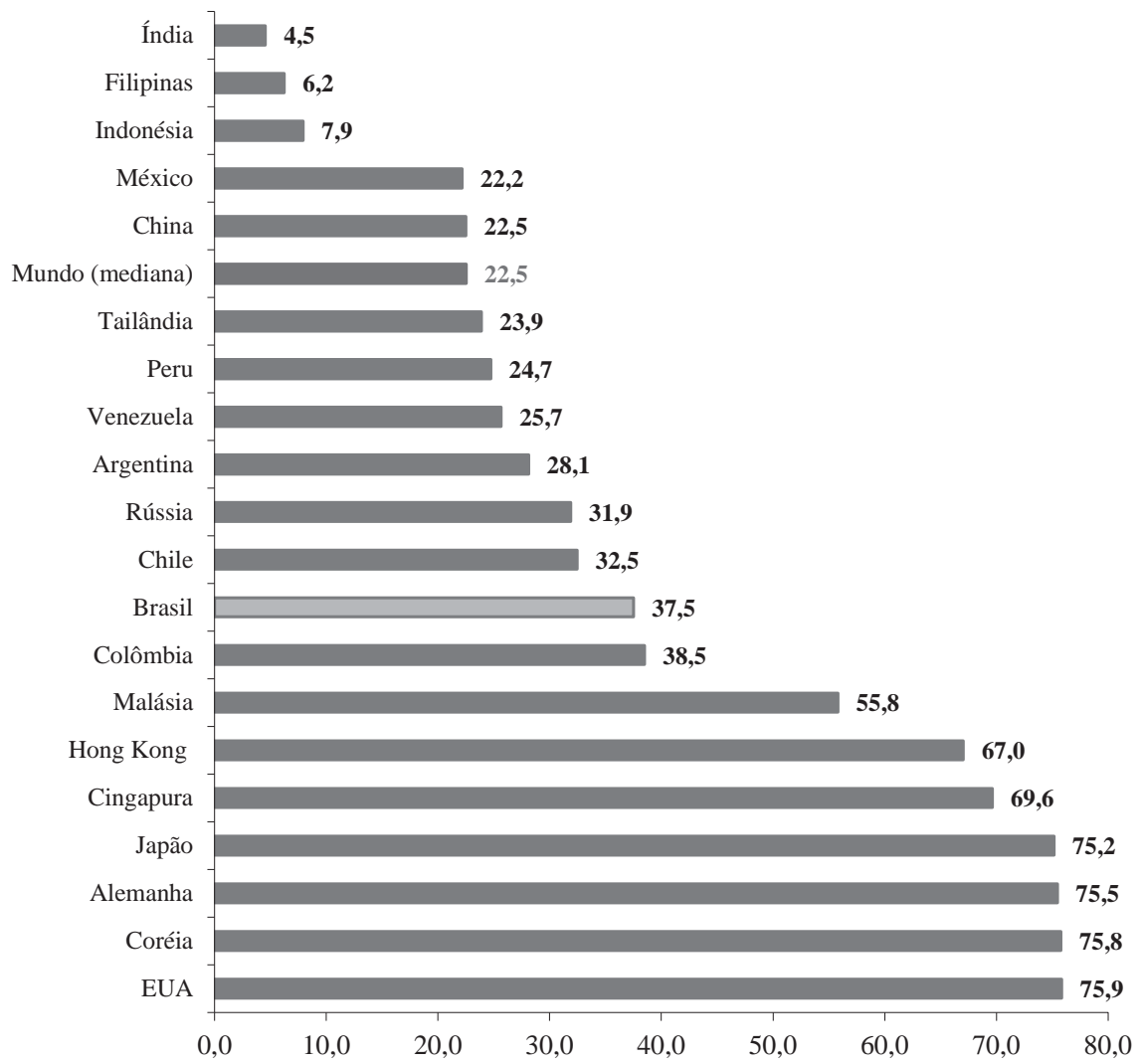

Fonte: World Development Indicators on Line, World Bank. Disponível em: <http://data.worldbank.org/ topic $>$. Acesso em agosto de 2010. 


\section{Gráfico 10. Ranking de Competitividade de Economias Selecionadas - Doing Business 2009}

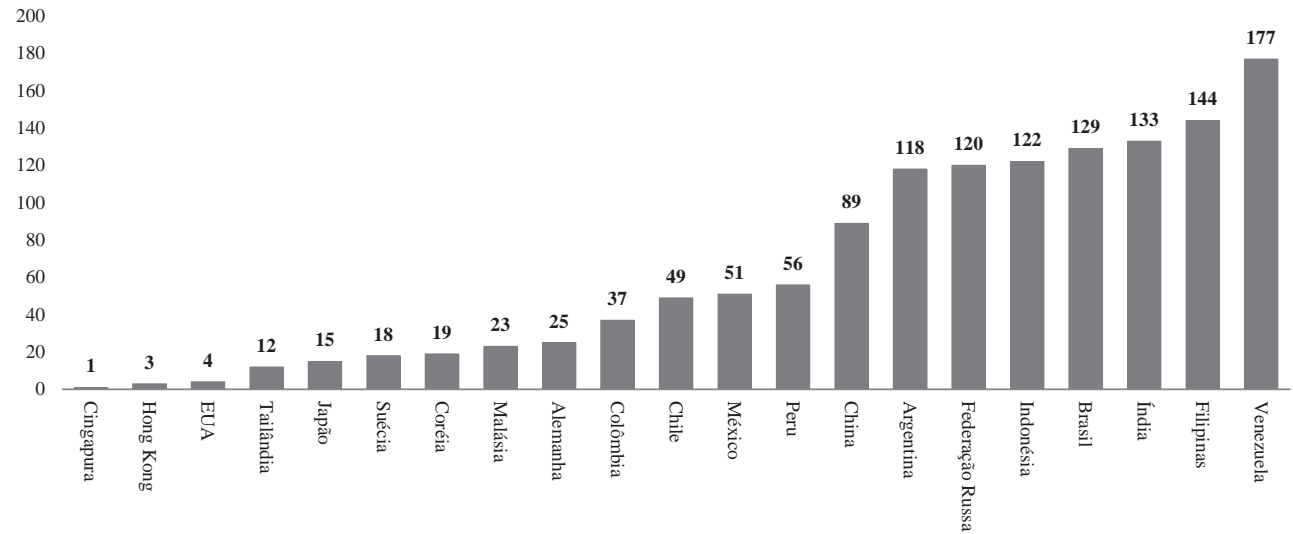

Fonte: World Development Indicators on Line, World Bank. Disponível em: <http://data.worldbank.org/ topic> Acesso em: ago. 2010.

O ranking se refere ao relatório "Doing Business 2007" e avalia a qualidade do ambiente institucional onde as empresas operam. Foram avaliados 181 países. O primeiro do ranking apresenta o melhor ambiente de negócios. 